\title{
Change in Risk and Bargaining Game
}

\author{
Hailin Sun* Sanxi $\mathrm{Li}^{\dagger} \quad$ Tong Wang ${ }^{\ddagger}$
}

December 5, 2012

\begin{abstract}
This paper studies the comparative statics regarding changes in risk on Nash's solution to bargaining games with stochastic outcome and disagreement points. When absolute risk tolerance is linear with constant slope, the Nash's solution to bargaining with risky outcomes and risky disagreement points can be viewed as division of divisible certainty equivalent between two risk-averse agents. We show that whether a deterioration of a bargainer's risky prospect is advantageous to his opponent often depends on whether preference displays decreasing absolute risk aversion (DARA). Specifically, for perfectly correlated risky prospects, DARA à la Arrow-Pratt works to the concavity of the joint certainty equivalent with respect to a bargainer's initial wealth or size of risky exposure; for independent risky prospects, DARA à la Ross vulnerates his risk bearing under Rothschild-Stiglitz increase in risk taking the form of adding an independent noise, both leading to the bargainer's increased propensity for risk aversion as well as the joint size of the pie. These results illuminate how individual risky prospect as well as risk preference influence the cooperating partners' income shares and thus the market equilibrum of marriage formation. We also show that this result is robust under Rubinstein's non-cooperative bargaining game.
\end{abstract}

*Toulouse School of Economics, 21, Allée de Brienne, 31000 Toulouse, France. Email: hailinsun@gmail.com

${ }^{\dagger}$ Toulouse School of Economics, 21, Allée de Brienne, 31000 Toulouse, France. Phone: +33 (0)5 343076 91. Email: lisanxi@gmail.com

${ }^{\ddagger}$ Centre for Competition Policy, University of East Anglia, NR4 7TJ Norwich, Norfolk UK. Phone: +44 (0) 7449892 383. Email: T.Wang3@uea.ac.uk 
Keywords Bargaining, the Nash Solution, Rubinstein Bargaining Solution, risk sharing, change in risk, decreasing absolute risk aversion

JEL Classification C70, C87, D81

\section{Introduction}

There is emerging consensus that efficient risk sharing across larger units is rejected (Townsend, 1994), however, individuals have shown to construct non-market institutions such as inter vivos transfers within families for consumption insurance. (Kotlikoff and Spivak, 1981; Rosenzweig, 1988; Rosenzweig and Stark, 1989; Ligon et al., 2002; Fafchamps and Lund, 2003; Ayalew, 2003; Hess, 2004; Pollak, 1985). Marriage has intrinsic advantage in enforcement and monitoring, which allows the household to make ex-ante efficient decisions that are not necessarily ex-post time-consistent for both partners under all realizations of uncertainty. Yet, it is also recognizably constituted of actors with conflicting interests and thus the resulting intrahousehold allocation depends on the members' relative bargaining power and their differential fall-back positions.

Other circumstances fit into this picture include joint venture agreements. As stock turns a less attractive commodity and merger and acquisition deals declines, strategic alliances and joint ventures are becoming increasingly popular as reduced sites of uncertainty. In joint ventures, two or more "parents" from related business or geographic markets agree to share resources to create a new entity which is jointly operated for mutual benefit. The amount of control exerted over the new entity typically depends on the parents' relative bargaining strengths as well as their risk preferences and pre-existing risky projects.

A frequently cited proposition in the bargaining literature asserts that an increase in one's degree of risk aversion improves the position of one's opponent. Intuitively, the subjective possibility of strategically reaching disagreement and its costly consequence makes risk aversion disadvantageous in bargaining, except in situations in which every potential agreement has a positive probability of yielding to one of the bargainers an outcome worse than disagreements (Kannai, 1977; Roth, 1977, 1978, 1979, 1985, 1985b, 1989; Kihlstrom, Roth and Schmeidler, 1981; Roth and Rothblum, 1982; Sobel, 1981; Riddell, 1981; Safra, Zhou and Zilcha, 1990). The connection of attributes of risky prospect to bargaining is less examined. Conven- 
tional wisdom suggests that deterioration of a bargainer's income decreases his share of the pie, however, risk aversion is not sufficient to guarantee an increase in his opponent's final payoff. The effect of a bargainer's initial wealth and risky exposure on risk-sharing agreements is typically correlated with higher-order properties of utility function. The purpose of this paper is to examine the comparative statics regarding changes in initial wealth and changes in risk on Nash's solution to bargaining games with stochastic outcomes and disagreement points.

We show that if absolute risk tolerance is linear with constant slope, the Nash's solution to bargaining with risky outcomes and risky disagreement points can be viewed as division of certainty equivalent between two risk-averse agents. A sure reduction in a bargainer's income inevitably lowers his payoff (in the certainty-equivalent space) which, under DARA, serves to increase his risk aversion. In addition, for perfectly correlated risky prospects, DARA à la Arrow-Pratt (Arrow, 1971) works to the concavity of net certainty equivalent with respect to the bargainer's initial wealth or size of risky exposure; for independent risky prospects, DARA à la Ross (1981) vulnerates his risk-bearing under independent Rothschild-Stiglitz (1970) marginal increase in risk. The above results guarantees an increase in his opponent's bargaining strength associated with risk aversion as well as the joint size of the pie, and ultimately the opponent's payoff. The analysis performed in this paper illuminates how important individual risky prospect as well as risk preference influence the cooperating entities' income shares. The predicted outcome can be used to examine the market equilibrium of partnership formation, in which the agents will commit to rules for insurance prior to the realization of the state of nature.

This paper is part of the game-theoretic literature on the comparative statics regarding uncertainty on the outcome of bargaining. In Nash's (1950) axiomatic single period bargaining model concerning the distribution of a divisible commodity between two risk-averse agents, Kannai (1977) showed that the payoff which Nash's solution assigns to a bargainer increases as his opponent becomes more risk averse in the sense of Arrow-Pratt. Roth (1977) and Thomson (1980) independently generalized the notion of Shapley value to certainty-equivalent of strategically risk-neutral agents participating in a bargaining process where there is subjective probability in reaching agreement at certain outcomes. Roth (1978) and Kihlstrom, Roth, and Schmeidler (1981) considered the bargaining situation of selecting an outcome from a set of riskless outcomes in the models of Nash (1950), Kalai and Smorodinsky (1975) and Perles and Maschler (1981). Sobel (1981) elaborated the results to bargaining 
over the distribution of several divisible commodities. In a strategic multiperiod bargaining model of Rubinstein (1982), Roth (1985) showed that risk aversion within each period has the same effect on the predicted outcome of bargaining. All the above results confirm risk aversion to be disadvantageous in bargaining whose potential outcomes involve no probabilistic risk.

Roth and Rothblum (1982) have dealt with the case in which bargaining is over risky outcome and riskless disagreement. They found that risk aversion is disadvantageous except in situations where disagreement outcome is preferred to potential agreement by one of the bargainers with positive probability. Safra, Zhou and Zilcha (1990) included risky disagreement points and impose further restriction on the degree of change in risk aversion for the result to hold. Instead of risk posture, Riddell (1981) examined the comparative statics effects of increase in uncertainty on several bargaining solutions. In a situation where changes in uncertainty only concern with changes in the probability of the state of the world (and thus both bargainers' disagreement points), he found changes in uncertainty irrelevant to the outcomes of bargaining. The current paper is one of the first attempts to analyze the influence of individual asset position and Rothschild-Stiglitz change in risk on the predicted bargaining outcome. We conduct our analysis in a single period Nash bargaining model concerning the division of the pooled income from two risky prospects. We then check the robustness of our results under Rubinstein's alternating-offer bargaining game.

The predictions regarding changes in risk on the bargaining outcomes are important, because they connect the theory of bargaining with the most important hypotheses regarding decision making under multiple sources of risks. In a multiplicative model where individuals' pre-existing risks are perfectly correlated, pooling multiple risks are self-aggravating in the sense that joint risk premium is a convex function of the joint size of the risks (Eeckhoudt and Gollier, 2001). In an additive model where individuals' pre-existing risks are independent, risk vulnerability guarantees that adding an exogenous unfair background risk raises risk aversion with respect to any other independent risk (Gollier and Pratt, 1996). The current paper shows that when absolute risk tolerance is increasing and linear with constant slope, the shape of the monetary value for the pooled risky prospects with respect to initial wealth or joint size of risks and the concepts of risk vulnerability are central to the explanation of the predicted bargaining outcome.

A recent paper by White (2008) studies how the existence of risk in bargaining 
agreements affects the outcome of negotiations in Rubinstein's alternating-offer bargaining game. Surprisingly, she finds that under reasonable conditions, a risk averse bargainer increases his bargaining power and thereby gets a larger share of the pie when the agreement is riskier. The bargaining power can even be increased so much that he becomes strictly better off. There are two key differences between her paper and ours. First, the risk that she considers only emerges when agreement is reached. In the case of disagreement, agents receive riskless outside options. In our paper, the risk under concern is not from the agreement. Each agent's individual risk is the same no matter whether agreement is reached. Secondlly, she does not consider efficient risk sharing between the two bargainers: all the risks following the agreement are born by the bargainers separately. We suggest that once the barrier to efficient risk sharing is removed, her results might be reversed.

The paper is organized as follows. The bargaining game is presented in Section 2. We show that if absolute risk tolerance is linear with constant slope, Nash's solution to bargaining with risky outcomes and risky disagreement points can be viewed as division of certainty equivalent between two risk-averse agents. We then give an example where a bargainer may be hurt by an increase of his opponent's risk when no further restriction is imposed other than risk aversion. Section 3 examined the situation where individuals' risks are perfectly correlated. Our result argues that under DARA deterioration of risk is advantageous to one's opponent. We derive stronger restrictions on utility function in Section 4 where individuals' risks are independent. In section 5, we apply the results in a simple market game of marriage formation. In section 6 , we check the robustness of the result with the Rubinstein bargaining solution and with the case where there is cooperation benefit from synergy. We conclude in Section 7.

\section{The Nash Bargaining Game}

Consider a potential partnership where two agents endowed with random prospects $\tilde{y}_{1}, \tilde{y}_{2}$ have the option to sign an agreement for sharing some synergy benefit $B$ as well as their random income. Cooperation therefore has two benefits: synergy and risk sharing. Agents can commit to reach an agreement prior to the realization of the state of nature and such agreement, if reached, is binding on both agents. We analyze this cooperative arrangement as a two-person single-period bargaining 
problem following Nash (1950). Denote $\tilde{Y}={ }_{d} \tilde{y}_{1}+\tilde{y}_{2}+B, \forall Y \in(0, \infty)$ as the joint income bargained over by two agents. Both of them are expected utility maximizers with respect to homogeneous probabilistic belief, and identically risk averse with vNM utility function $u(w):[0, \infty) \rightarrow \mathbb{R}$ which is bounded and continuously differentiable in $w \cdot u^{\prime}(w)>0, u^{\prime \prime}(w)<0$ for all $w \in(0, \infty)$. Assume preference belongs to the class of Harmonious Absolute Risk Aversion (HARA), i.e., $t(w) \triangleq-u^{\prime}(w) / u^{\prime \prime}(w)=$ $\frac{1}{\gamma} w+\frac{1}{\alpha}$. The coefficient $t(w)$, i.e. the reciprocal of Arrow-Pratt measure of absolute risk aversion, is called the absolute risk tolerance. In particular, preference exhibits Decreasing / Increasing Absolute Risk Aversion (DARA/IARA) if $\gamma>0$ $(\gamma<0)$, Constant Absolute Risk Aversion (CARA) if $\gamma \rightarrow \infty$, Constant Relative Risk Aversion (CRRA) if $\alpha \rightarrow \infty$, and Risk Neutral if $\gamma \rightarrow 0$.

The bargaining game is defined by a pair $(S, d)$ where $S=\{(E u(s(\tilde{Y})), E u(\tilde{Y}-$ $s(\tilde{Y}))) \mid 0 \leq s(Y) \leq Y\}$ is the set of (unanimously agreed) feasible expected utility payoffs to the agents, $d=\left(E u\left(\tilde{y}_{1}\right), E u\left(\tilde{y}_{2}\right)\right) \in S$ is the disagreement points, and $s(Y)$ is the risk sharing rule that maps each realized value of $\tilde{Y}$ to agent 1's individual share. Nash's solution will specify risk-sharing rules $\hat{s}(Y)$ which solves the following problem

$$
\mathbf{P 1} \quad \max _{s(Y)}\left(\left(E u(s(\tilde{Y}))-E u\left(\tilde{y}_{1}\right)\right) \cdot\left(E u(\tilde{Y}-s(\tilde{Y}))-E u\left(\tilde{y}_{2}\right)\right)\right)
$$

and yields the bargaining outcomes $F_{1}(S, d)=E u(\hat{s}(\tilde{Y})), F_{2}(S, d)=E u(\tilde{Y}-\hat{s}(\tilde{Y}))$ to agent 1 and 2 respectively.

Now assume agent 2's random prospect suffers a deterioration: a sure reduction or an increase in risk. Throughout the paper, we use the superscript "**" to denote the corresponding variables after the deterioration. Let $\tilde{y}_{2}^{*}$ denote agent 2's random prospect after the deterioration, and the new bargaining model is $\left(S^{*}, d^{*}\right)$, with $S^{*}=\left\{\left(E u\left(s\left(\tilde{Y}^{*}\right)\right), E u\left(\tilde{Y}^{*}-s\left(\tilde{Y}^{*}\right)\right)\right) \mid 0 \leq s(Y) \leq Y\right\}, \tilde{Y}^{*}={ }_{d} \tilde{y}_{1}+\tilde{y}_{2}^{*}+B$ and $d^{*}=\left(E u\left(\tilde{y}_{1}\right), E u\left(\tilde{y}_{2}^{*}\right)\right.$. We assume this deterioration does not affect the cooperation benefit from synergy $B$. The question that is central to the present paper is: will agent 1 be better off under the new bargaining game $\left(S^{*}, d^{*}\right)$ ?

Problem P1 concerning risk-sharing rules is not easy to solve. However, it is well known that if absolute risk tolerance is linear, the Pareto frontier in the monetaryequivalent space is a straight line and the monetary value of the joint pie is distributional free, i.e., the sum of two agents' certainty equivalent is constant for any efficient risk sharing rule and does not depend on the weights given to the agents (see Appendix for a proof). Thus the Nash's solution to bargaining with risky out- 
comes and risky disagreement points can be viewed as division of a fixed amount of certainty equivalent between two risk-averse agents.

Denote $C$ as the total certainty equivalent bargained over by two agents, $C_{1}$, $C_{2}$ as their respective share, and $C_{1}^{d} \triangleq u^{-1}\left(E u\left(\tilde{y}_{1}\right)\right), C_{2}^{d} \triangleq u^{-1}\left(E u\left(\tilde{y}_{2}\right)\right)$ as their disagreement payoffs in monetary terms. Since $C$ is free of weights, we might as well adopt the half-half division ${ }^{1}$, i.e., each spouse will take care of half of the pooled income: $s(Y)=\frac{Y}{2}$. By definition $u\left(\frac{C}{2}\right)=E u\left(\frac{\tilde{Y}}{2}\right)$ and thus $C=2 u^{-1}\left(E u\left(\frac{\tilde{Y}}{2}\right)\right)$. The net surplus in terms of certainty equivalent is $N C=C-\left(C_{1}^{d}+C_{2}^{d}\right)>0$ : efficient risk sharing enlarges the size of the pie shared by the two agents. In the following of this paper, whenever we say "the size of the pie", we refer to the net surplus $N C$.

Since Nash solution is Pareto optimal and satisfies the axiom of independence of irrelevant alternatives, we can restrict our attention on the Pareto frontier which, under this transformation, is given by $S^{P}=\left\{\left(u\left(C_{1}\right), u\left(C_{2}\right)\right) \mid C_{1} \geq 0, C_{2} \geq 0, C_{1}+\right.$ $\left.C_{2}=C\right\}^{2}$. It can be proved that there exists a unique Nash solution on $S^{P}$ and the solution $\left(\hat{C}_{1}(S, d), \hat{C}_{2}(S, d)\right)^{3}$ (in the certainty-equivalent space) can be obtained from the following maximization problem (See appendix for proof):

\section{P2}

$$
\begin{gathered}
\max _{\left(C_{1}, C_{2}\right)}\left(\left(u\left(C_{1}\right)-u\left(C_{1}^{d}\right)\right) \cdot\left(u\left(C_{2}\right)-u\left(C_{2}^{d}\right)\right)\right) \\
\text { s.t. } C_{1}+C_{2}=C
\end{gathered}
$$

From the constraint we have $C_{2}=C-C_{1}$. Substituting it into the original maximization problem and taking the F.O.C. with respect to $C_{1}$ gives:

$$
u^{\prime}\left(C_{1}\right)\left[u\left(C_{2}\right)-u\left(C_{2}^{d}\right)\right]-u^{\prime}\left(C_{2}\right)\left[u\left(C_{1}\right)-u\left(C_{1}^{d}\right)\right]=0
$$

which, after rearranging, yields $\frac{u^{\prime}\left(C_{1}\right)}{u^{\prime}\left(C_{2}\right)}=\frac{u\left(C_{1}\right)-u\left(C_{1}^{d}\right)}{u\left(C_{2}\right)-u\left(C_{2}^{d}\right)}$ i.e., the ratio of the marginal utilities evaluated at the certainty-equivalent bargaining outcomes equals the ratio of the net shares of the pie in terms of expected utility.

Now consider the effect of replacing agent 2's risky prospect with a deteriorated one, $\tilde{y}_{2}^{*}$. The deterioration has two effects. First, it reduces the sum of the certainty

\footnotetext{
${ }^{1}$ Half-half sharing rule is Pareto efficient because the two agents have identical utility function.

${ }^{2}$ Independence of irrelevant alternatives means that the solution to the bargaining problem does not change if the utility possibilities set is unfavorably altered such that the disagreement point is unchanged and the original solution remains feasible; that is, if $(S, d)$ and $\left(S^{\prime}, d\right)$ are bargaining problem and $S^{\prime} \subset S$, and the solution of $(S, d)$ also belongs to $S^{\prime}$, then the two bargaining problems have the same solution.

${ }^{3} C_{1}, C_{2}$, etc will be used in lieu of $\hat{C}_{1}(S, d), \hat{C}_{2}(S, d)$ in much of what follows.
} 
equivalent. Denote the reduced amount as $\Delta C=C-C^{*}$. Second, it also reduces the disagreement certainty equivalent of agent 2. Denote the reduced amount as $\Delta C_{2}^{d}=C_{2}^{d}-C_{2}^{d *}$. The reduced amount of the size of the pie, i.e., the net surplus, is hence $\Delta N C=\Delta C-\Delta C_{2}^{d}$. When $\Delta N C>0$, the size of the pie decreases after the deterioration; when $\Delta N C<0$, the size of the pie increases after the deterioration. The expected utility which Nash's solution assigns to agent 1 increases as agent 2's project becomes more risky if

$$
u^{\prime}\left(C_{1}\right)\left[u\left(C^{*}-C_{1}\right)-u\left(C_{2}^{d *}\right)\right]-u^{\prime}\left(C^{*}-C_{1}\right)\left[u\left(C_{1}\right)-u\left(C_{1}^{d}\right)\right]>0
$$

which, by using the expression of $\Delta C$ and $\Delta C_{2}^{d}$ and noticing that $C=C_{1}+C_{2}$, rewrites as:

$$
u^{\prime}\left(C_{1}\right)\left[u\left(C_{2}-\Delta C\right)-u\left(C_{2}^{d}-\Delta C_{2}^{d}\right)\right]-u^{\prime}\left(C_{2}-\Delta C\right)\left[u\left(C_{1}\right)-u\left(C_{1}^{d}\right)\right]>0 .
$$

Rearranging the above inequality writes:

$$
\phi(\Delta C)+u^{\prime}\left(C_{1}\right)\left[u\left(C_{2}^{d}-\Delta C\right)-u\left(C_{2}^{d}-\Delta C_{2}^{d}\right)\right]>0
$$

where $\phi(\Delta C) \triangleq u^{\prime}\left(C_{1}\right)\left[u\left(C_{2}-\Delta C\right)-u\left(C_{2}^{d}-\Delta C\right)\right]-u^{\prime}\left(C_{2}-\Delta C\right)\left[u\left(C_{1}\right)-u\left(C_{1}^{d}\right)\right]$. Notice that when the size of the pie does not change, i.e., $\Delta C=\Delta C_{2}^{d}$, the second term of the LHS of inequality (2) vanishes and (2) becomes $\phi(\Delta C)>0$. In examining the impact of deterioration in risky prospect on the opponent's bargaining payoff, two effects are to be considered: the first one, by assuming agent 2's disagreement certainty equivalent reduced by the amount of the reduced total certainty equivalent so that the size of the pie remains unchanged, reflects the net effect of changes in bargainer's threat point, as captured by $\phi(\Delta C)$; the second one reflects the effect caused by the change in the size of the pie, i.e., $\Delta C \neq \Delta C_{2}^{d}$, as captured by the second term of the LHS of (2). The following Lemma shows that DARA plays an important role.

Lemma $1 \phi(\Delta C)$ is positive/negative if preference exhibits DARA/IARA

Proof. From (1), we have $u\left(C_{1}\right)-u\left(C_{1}^{d}\right)=\frac{u^{\prime}\left(C_{1}\right)\left[u\left(C_{2}\right)-u\left(C_{2}^{d}\right)\right]}{u^{\prime}\left(C_{2}\right)}$. Substituting into the expression of $\phi(\Delta C)$, we get

$$
\phi(\Delta C)=u^{\prime}\left(C_{2}-\Delta C\right) u^{\prime}\left(C_{1}\right)\left(\frac{u\left(C_{2}-\Delta C\right)-u\left(C_{2}^{d}-\Delta C\right)}{u^{\prime}\left(C_{2}-\Delta C\right)}-\frac{u\left(C_{2}\right)-u\left(C_{2}^{d}\right)}{u^{\prime}\left(C_{2}\right)}\right)>0
$$


iff $\psi \triangleq \frac{u\left(C_{2}-\Delta C\right)-u\left(C_{2}^{d}-\Delta C\right)}{u^{\prime}\left(C_{2}-\Delta C\right)}$ is increasing in $\Delta C$. Denote $A(w)=-u^{\prime \prime}(w) / u^{\prime}(w)$ as the absolute risk aversion. We have

$$
\begin{aligned}
\frac{\partial \psi}{\partial(\Delta C)}= & -\frac{\left[u^{\prime}\left(C_{2}-\Delta C\right)-u^{\prime}\left(C_{2}^{d}-\Delta C\right)\right] u^{\prime}\left(C_{2}-\Delta C\right)}{\left.u^{\prime 2}\left(C_{2}-\Delta C\right)\right] u^{\prime \prime}\left(C_{2}-\Delta C\right)} \\
& +\frac{\left[u\left(C_{2}-\Delta C\right)-u\left(C_{2}^{d}-\Delta C\right)\right.}{u^{\prime 2}\left(C_{2}-\Delta C\right)} \\
= & -\frac{\left[u^{\prime}\left(C_{2}-\Delta C\right)-u^{\prime}\left(C_{2}^{d}-\Delta C\right)\right]+A\left(C_{2}-\Delta C\right)\left[u\left(C_{2}-\Delta C\right)-u\left(C_{2}^{d}-\Delta C\right)\right]}{u^{\prime}\left(C_{2}-\Delta C\right)} \\
= & -\frac{\int_{C_{2}^{d}-\Delta C}^{C_{2}-\Delta C} u^{\prime \prime}(t) d t+\int_{C_{2}^{d}-\Delta C}^{C_{2}-\Delta C} A\left(C_{2}-\Delta C\right) u^{\prime}(t) d t}{u^{\prime}\left(C_{2}-\Delta C\right)} \\
= & -\frac{\int_{C_{2}^{d}-\Delta C}^{C_{2}-\Delta C}\left[-A(t) u^{\prime}(t)\right] d t+\int_{C_{2}^{d}-\Delta C}^{C_{2}-\Delta C} A\left(C_{2}-\Delta C\right) u^{\prime}(t) d t}{u^{\prime}\left(C_{2}-\Delta C\right)} \\
= & -\frac{\int_{C_{2}^{d}-\Delta C}^{C_{2}-\Delta C}\left[A\left(C_{2}-\Delta C\right)-A(t)\right] u^{\prime}(t) d t}{u^{\prime}\left(C_{2}-\Delta C\right)}
\end{aligned}
$$

which is positive if $A$ is decreasing, and negative if $A$ is increasing.

The above Lemma states that, a deterioration in agent 2's risky prospect, if it doesn't affect the net bargaining surplus, i.e., $\Delta C=\Delta C_{2}^{d}$, will make agent 1 better off under DARA preference. This result is consistent with the prevailing predictions on Nash's solution with risk-averse agents: risk aversion benefits one's opponent (Kihlstrom, Roth, and Schmeidler, 1981; Roth, 1979, among others). Indeed, a deterioration in a bargainer's risky prospect raises his risk aversion under DARA. Disagreement has costly consequences and the desire to avoid the risk of disagreement is reflected in the final bargaining outcome. A more risk-averse agent has a stronger desire to avoid such risk hence is willing to give up more share during the bargaining, in order to facilitate reaching an agreement. Lemma 1 immediately gives the following proposition.

Proposition 1 If preference exhibits DARA and $\Delta C \leq \Delta C_{2}^{d}$, then $F_{1}\left(S^{*}, d^{*}\right)>$ $F_{1}(S, d)$; if preference exhibits IARA and $\Delta C \geq \Delta C_{2}^{d}$, then $F_{1}\left(S^{*}, d^{*}\right)<$ $F_{1}(S, d)$

The above proposition gives a sufficient condition for a bargainer's deterioration of risky prospect to be advantageous or disadvantageous to his opponent. An agent benefits from a deterioration of his opponent's risky prospect if preference exhibits DARA and the net bargaining surplus increases; in contrast, he suffers if preference exhibits IARA and the net bargaining surplus decreases. We conclude this section with an example showing that DARA alone is not sufficient for the prediction that a bargainer's deterioration of risky prospect to be advantageous to his opponent to hold. 
Example 1 Suppose agent 1 is endowed with a risky project $\tilde{y}_{1}=w_{1}+\tilde{\varepsilon}$ and agent 2 a riskless project $y_{2}=w_{2}$, where $\tilde{\varepsilon}$ is small risk with $E(\tilde{\varepsilon})=0$ and $\operatorname{Var}(\tilde{\varepsilon})=\sigma^{2}$. Moreover, assume $B=0$. We want to determine whether agent 1 is better off when $w_{2}$ decreases. By applying Arrow-Pratt approximation to $C=2 u^{-1}\left(E u\left(\frac{\tilde{Y}}{2}\right)\right)$ we have that $C=w_{1}+w_{2}-\frac{1}{4} A\left(\frac{w_{1}+w_{2}}{2}\right) \sigma^{2}$. Denote $L$ as the LHS of (1). We know that the usual prediction won't hold if $\frac{\partial L}{\partial w_{2}}>0$, and if this is the case, $\frac{\partial C_{1}}{\partial w_{2}}=-\frac{\partial L}{\partial C_{1}} / \frac{\partial L}{\partial w_{2}}>0$, i.e., a reduction in agent 2 's fixed profit makes agent 1 worse off. Indeed, noticing that $C_{2}=C-C_{1}$ and $C_{2}^{d}=w_{2}$, we have

$$
\begin{aligned}
& \frac{\partial L}{\partial w_{2}}=u^{\prime}\left(C_{1}\right)\left[u^{\prime}\left(C_{2}\right) \frac{\partial C}{\partial w_{2}}-u^{\prime}\left(C_{2}^{d}\right)\right]-u^{\prime \prime}\left(C_{2}\right) \frac{\partial C}{\partial w_{2}}\left[u\left(C_{1}\right)-u\left(C_{1}^{d}\right)\right] \\
&=u^{\prime}\left(C_{1}\right)\left[u^{\prime}\left(C_{2}\right) \frac{\partial C}{\partial w_{2}}-u^{\prime}\left(C_{2}^{d}\right) \frac{\partial C}{\partial w_{2}}+u^{\prime}\left(C_{2}^{d}\right)\left(\frac{\partial C}{\partial w_{2}}-1\right)\right] \\
&-u^{\prime \prime}\left(C_{2}\right) \frac{\partial C}{\partial w_{2}}\left[u\left(C_{1}\right)-u\left(C_{1}^{d}\right)\right] \\
&=\left\{u^{\prime}\left(C_{1}\right)\left[u^{\prime}\left(C_{2}\right)-u^{\prime}\left(C_{2}^{d}\right)\right]-u^{\prime \prime}\left(C_{2}\right)\left[u\left(C_{1}\right)-u\left(C_{1}^{d}\right)\right]\right\} \frac{\partial C}{\partial w_{2}} \\
&+u^{\prime}\left(C_{1}\right) u^{\prime}\left(C_{2}^{d}\right)\left(\frac{\partial C}{\partial w_{2}}-1\right) \\
&=u^{\prime}\left(C_{1}\right)\left\{u^{\prime}\left(C_{2}\right)-u^{\prime}\left(C_{2}^{d}\right)-u^{\prime \prime}\left(C_{2}\right) \frac{\left[u\left(C_{2}\right)-u\left(C_{2}^{d}\right)\right]}{u^{\prime}\left(C_{2}\right)}\right\} \frac{\partial C}{\partial w_{2}} \\
&+u^{\prime}\left(C_{1}\right) u^{\prime}\left(C_{2}^{d}\right)\left(\frac{\partial C}{\partial w_{2}}-1\right) \\
&=u^{\prime}\left(C_{1}\right) \int_{C_{2}^{d}}^{C_{2}}\left(A\left(C_{2}\right)-A(t)\right) u^{\prime}(t) d t \frac{\partial C}{\partial w_{2}}+u^{\prime}\left(C_{1}\right) u^{\prime}\left(C_{2}^{d}\right)\left(\frac{\partial C}{\partial w_{2}}-1\right) .
\end{aligned}
$$

The fourth equality uses the equality $u\left(C_{1}\right)-u\left(C_{1}^{d}\right)=\frac{u^{\prime}\left(C_{1}\right)\left[u\left(C_{2}\right)-u\left(C_{2}^{d}\right)\right]}{u^{\prime}\left(C_{2}\right)}$ derived from (1). The above result implies:

$$
\begin{aligned}
& \lim _{\sigma^{2} \rightarrow 0}\left(\frac{\partial L}{\partial w_{2}} \frac{1}{u^{\prime}\left(C_{1}\right) \sigma^{2}}\right) \\
= & \lim _{\sigma^{2} \rightarrow 0}\left(\frac{\partial C}{\partial w_{2}} \frac{\int_{C_{2}^{d}}^{C_{2}}\left(A\left(C_{2}\right)-A(t)\right) u^{\prime}(t) d t}{\sigma^{2}}+\frac{\frac{\partial C}{\partial w_{2}}-1}{\sigma^{2}} u^{\prime}\left(C_{2}^{d}\right)\right) \\
= & \left.\frac{\partial C}{\partial w_{2}} \frac{\partial}{\partial \sigma^{2}}\right|_{\sigma^{2}=0} \int_{C_{2}^{d}}^{C_{2}}\left(A\left(C_{2}\right)-A(t)\right) u^{\prime}(t) d t+\left.\frac{\partial^{2} C}{\partial w_{2} \partial \sigma^{2}}\right|_{\sigma^{2}=0} u^{\prime}\left(C_{2}^{d}\right) \\
= & -\frac{1}{8} A^{\prime}\left(\frac{w_{1}+w_{2}}{2}\right) u^{\prime}\left(C_{2}^{d}\right) .
\end{aligned}
$$


which is strictly positive if $A$ is decreasing. The last equality follows because

$$
\begin{aligned}
& \left.\frac{\partial}{\partial \sigma^{2}}\right|_{\sigma^{2}=0} \int_{C_{2}^{d}}^{C_{2}}\left(A\left(C_{2}\right)-A(t)\right) u^{\prime}(t) d t \\
& =\left.\int_{C_{2}^{d}}^{C_{2}} \frac{\partial}{\partial \sigma^{2}}\left(A\left(C_{2}\right)-A(t)\right) u^{\prime}(t) d t\right|_{\sigma^{2}=0}+\left.\left(A\left(C_{2}\right)-A\left(C_{2}\right)\right) u^{\prime}\left(C_{2}\right)\right|_{\sigma^{2}=0} \\
& =\int_{C_{2}^{d}}^{C_{2}^{d}} \frac{\partial}{\partial \sigma^{2}}\left(A\left(C_{2}\right)-A(t)\right) u^{\prime}(t) d t=0 .
\end{aligned}
$$

By continuity, $\frac{\partial L}{\partial w_{2}} \frac{1}{u^{\prime}\left(C_{1}\right) \sigma^{2}}$ and therefore $\frac{\partial L}{\partial w_{2}}$ is strictly positive for $\sigma^{2}$ sufficiently small, if $A$ is decreasing.

The example shows that if a deterioration of agent 2's prospect reduces the net bargaining surplus, then agent 1 might be worse-off. Intuitively, although he will gain a larger portion of the pie as his opponent becomes more risk-averse, the size of the pie might be significantly reduced. The total effect will be ambiguous. Notice further that the size of the pie is reduced by $\Delta C-\Delta C_{2}^{d}$. Hence, the size of the pie will be significantly reduced if $\Delta C_{2}^{d}$ is very small. Under DARA, $\Delta C_{2}^{d}$ is more likely to decrease as agent 2's starting riskiness decreases and thus at its minimum when agent 2 is initially riskless. Example 1 also suggests that for the answer to our central question to be positive, agent 2's starting risk should not be too small.

In the following sections, we first solve the problem in the case when $B=0$. That is, there is no synergy and the only benefit of cooperation is risk sharing. Then, in section 6.2 , we check that all our results hold for positive $B$.

\section{$3 \quad$ Perfectly Correlated Risks}

The sources of uncertainty considered in this paper include systematic risk which is associated with occurrences such as war, recession, inflation and fluctuating interest rates, and idiosyncratic shocks which only affect a particular project at a time. We examine the first environment in this section, and the second in the next section. Throughout this section, we assume that $\tilde{y}_{1}=w_{0}+\tilde{\varepsilon}, \tilde{y}_{2}=w_{0}+k \tilde{\varepsilon} . E(\tilde{\varepsilon})=0$, that is, agent's risks are perfectly correlated. 


\subsection{A Sure Reduction}

Consider the situation where $\tilde{y}_{2}$ is replaced by $\tilde{y}_{2}^{*}=w_{0}-\delta_{0}+k \tilde{\varepsilon}$. If the risk is small with $\operatorname{Var}(\tilde{\varepsilon})=\sigma^{2}$, by applying Arrow-Pratt approximation to $C=2 u^{-1}\left(E u\left(\frac{\tilde{Y}}{2}\right)\right)$ we have that $C=2 w_{0}-A\left(w_{0}\right)\left(\frac{1+k}{2}\right)^{2} \sigma^{2}, C^{*}=2 w_{0}-\delta_{0}-A\left(w_{0}-\frac{\delta_{0}}{2}\right)\left(\frac{1+k}{2}\right)^{2} \sigma^{2}$, $C_{2}^{d}=w_{0}-\frac{1}{2} A\left(w_{0}\right) k^{2} \sigma^{2}, C_{2}^{d *}=w_{0}-\delta_{0}-\frac{1}{2} A\left(w_{0}-\delta_{0}\right) k^{2} \sigma^{2}$. Hence

$$
\begin{aligned}
& \Delta C=\delta_{0}-\left(A\left(w_{0}\right)-A\left(w_{0}-\frac{\delta_{0}}{2}\right)\right)\left(\frac{1+k}{2}\right)^{2} \sigma^{2}, \\
& \Delta C_{2}^{d}=\delta_{0}-\frac{1}{2}\left(A\left(w_{0}\right)-A\left(w_{0}-\delta_{0}\right)\right) k^{2} \sigma^{2},
\end{aligned}
$$

and consequently

$$
\begin{aligned}
\Delta C-\Delta C_{2}^{d} & =k^{2}\left(A\left(w_{0}-\frac{\delta_{0}}{2}\right)-\frac{A\left(w_{0}-\delta_{0}\right)+A\left(w_{0}\right)}{2}\right) \sigma^{2} \\
& +\left(k^{2}-\left(\frac{1+k}{2}\right)^{2}\right)\left(A\left(w_{0}\right)-A\left(w_{0}-\frac{\delta_{0}}{2}\right)\right) \sigma^{2} .
\end{aligned}
$$

The first term is negative if $A$ is decreasing and convex. This is indeed the case when utility belongs to the HARA class and exhibit DARA. The second term is non-positive if $k \geq 1$ and $A$ is decreasing. Following Proposition 1, we conclude that when risk is small and utility exhibits DARA, a bargainer's sure reduction in profit benefits his opponent, given that his opponent's initial risk is not too small: $k \geq 1$.

Now we turn to the general case. Define $C E\left(k \tilde{\varepsilon}, w_{0}\right)$ as the certainty equivalent for $k$ units of risk $\tilde{\varepsilon}$ with certain background wealth $w_{0}$ which satisfies

$$
E u\left(w_{0}+k \tilde{\varepsilon}\right)=u\left(w_{0}+C E\left(k \tilde{\varepsilon}, w_{0}\right)\right)
$$

and related risk premium $\pi\left(k \tilde{\varepsilon}, w_{0}\right) \triangleq E k \tilde{\varepsilon}-C E\left(k \tilde{\varepsilon}, w_{0}\right)$. The following Lemma is useful.

Lemma 2 If preference belongs to the class of $H A R A$, then $\pi\left(k \tilde{\varepsilon}, w_{0}\right)$ is convex in both $k$ and $w_{0}$, i.e., $\frac{\partial^{2} \pi\left(k \tilde{\varepsilon}, w_{0}\right)}{\partial k^{2}} \geq 0$ and $\frac{\partial^{2} \pi\left(k \tilde{\varepsilon}, w_{0}\right)}{\partial w_{0}^{2}} \geq 0$. Moreover, the cross derivative of $\pi\left(k \tilde{\varepsilon}, w_{0}\right)$ with respect to $k$ and $w_{0}$ is negative: $\frac{\partial^{2} \pi\left(k \tilde{\varepsilon}, w_{0}\right)}{\partial k \partial w_{0}} \leq 0$.

Proof. Solving $C E\left(k \tilde{\varepsilon}, w_{0}\right)$ and therefore $\pi\left(k \tilde{\varepsilon}, w_{0}\right)$ from (3) and taking second partial derivative of $\pi\left(k \tilde{\varepsilon}, w_{0}\right)$ w.r.t. $k$, yields that $\frac{\partial^{2} \pi\left(k \tilde{\varepsilon}, w_{0}\right)}{\partial k^{2}} \geq 0$ iff

$$
-\frac{u^{\prime \prime}\left(u^{-1}\left(E u\left(w_{0}+k \tilde{\varepsilon}\right)\right)\right)}{\left[u^{\prime}\left(u^{-1}\left(E u\left(w_{0}+k \tilde{\varepsilon}\right)\right)\right)\right]^{2}} \leq-\frac{E\left(u^{\prime \prime}\left(w_{0}+k \tilde{\varepsilon}\right) \tilde{\varepsilon}^{2}\right)}{\left[E\left(u^{\prime}\left(w_{0}+k \tilde{\varepsilon}\right) \tilde{\varepsilon}\right)\right]^{2}}
$$


Solving from the expression of risk tolerance $t(w)=\frac{1}{\gamma} w+\frac{1}{\alpha}$, we have that $u^{\prime}(w)=$ $D_{1} t(w)^{-\gamma}$ and $u(c)=\frac{\gamma}{1-\gamma} D_{1} t(w)^{1-\gamma}+D_{2}$ where $D_{1}, D_{2}$ are constants.

Substituting into the above inequality yields that $\frac{\partial^{2} \pi\left(k \tilde{\varepsilon}, w_{0}\right)}{\partial k^{2}} \geq 0$ iff

$$
\left[E\left(t\left(w_{0}+k \tilde{\varepsilon}\right)^{-\gamma} \tilde{\varepsilon}\right)\right]^{2} \leq E\left(t\left(w_{0}+k \tilde{\varepsilon}\right)^{-(1+\gamma)} \tilde{\varepsilon}^{2}\right) E t\left(w_{0}+k \tilde{\varepsilon}\right)^{1-\gamma}
$$

which holds as a direct application of Cauchy-Schwarz inequality. The convexity of $\pi\left(k \tilde{\varepsilon}, w_{0}\right)$ in $w_{0}$ follows similarly. The proof of $\frac{\partial^{2} \pi\left(k \tilde{\varepsilon}, w_{0}\right)}{\partial k \partial w_{0}} \leq 0$ is much more complex and is given in the appendix.

The above Lemma characterizes the shape of the cost curve of risk. Eeckhoudt and Gollier (2001) have noticed that, in general, risk premium might not be convex in the size of risk and that DARA serves as a sufficient condition. The above result complements theirs by restricting preference to the class of HARA, while relaxing the condition of DARA.

Now we consider the general case with large risk. Since $C=2\left(w_{0}-\pi\left(\frac{1+k}{2} \tilde{\varepsilon}, w_{0}\right)\right)$, $C^{*}=2\left(w_{0}-\frac{\delta_{0}}{2}-\pi\left(\frac{1+k}{2} \tilde{\varepsilon}, w_{0}-\frac{\delta_{0}}{2}\right)\right), C_{2}^{d}=w_{0}-\pi\left(k \tilde{\varepsilon}, w_{0}\right), C_{2}^{d *}=w_{0}-\delta_{0}-$ $\pi\left(k \tilde{\varepsilon}, w_{0}-\delta_{0}\right)$, we have

$$
\Delta C=\delta_{0}+2\left(\pi\left(\frac{1+k}{2} \tilde{\varepsilon}, w_{0}-\frac{\delta_{0}}{2}\right)-\pi\left(\frac{1+k}{2} \tilde{\varepsilon}, w_{0}\right)\right)
$$

and

$$
\Delta C_{2}^{d}=\delta_{0}+\left(\pi\left(k \tilde{\varepsilon}, w_{0}-\delta_{0}\right)-\pi\left(k \tilde{\varepsilon}, w_{0}\right)\right)
$$

Hence,

$$
\begin{aligned}
\Delta C-\Delta C_{2}^{d} & =2\left(\pi\left(\frac{1+k}{2} \tilde{\varepsilon}, w_{0}-\frac{\delta_{0}}{2}\right)-\pi\left(\frac{1+k}{2} \tilde{\varepsilon}, w_{0}\right)\right)-\left(\pi\left(k \tilde{\varepsilon}, w_{0}-\delta_{0}\right)-\pi\left(k \tilde{\varepsilon}, w_{0}\right)\right) \\
& =2\left(\pi\left(\frac{1+k}{2} \tilde{\varepsilon}, w_{0}-\frac{\delta_{0}}{2}\right)-\frac{\pi\left(\frac{1+k}{2} \tilde{\varepsilon}, w_{0}\right)+\pi\left(\frac{1+k}{2} \varepsilon, w_{0}-\delta_{0}\right)}{2}\right) \\
& +\left(\left(\pi\left(\frac{1+k}{2} \tilde{\varepsilon}, w_{0}-\delta_{0}\right)-\pi\left(\frac{1+k}{2} \tilde{\varepsilon}, w_{0}\right)\right)-\left(\pi\left(k \tilde{\varepsilon}, w_{0}-\delta_{0}\right)-\pi\left(k \tilde{\varepsilon}, w_{0}\right)\right)\right) \\
& =2\left(\pi\left(\frac{1+k}{2} \tilde{\varepsilon}, w_{0}-\frac{\delta_{0}}{2}\right)-\frac{\pi\left(\frac{1+k}{2} \tilde{\varepsilon}, w_{0}\right)+\pi\left(\frac{1+k}{2} \varepsilon, w_{0}-\delta_{0}\right)}{2}\right) \\
& +\int_{w_{0}-\delta_{0}}^{w_{0}} \frac{\partial \pi(k \tilde{\varepsilon}, s)}{\partial w_{0}}-\frac{\partial \pi\left(\frac{1+k}{2} \tilde{\varepsilon}, s\right)}{\partial w_{0}} d s .
\end{aligned}
$$

The first term is negative if $\pi\left(\frac{1+k}{2} \tilde{\varepsilon}, w_{0}\right)$ is increasing and convex in $w_{0}$. The second term is negative for $k>1$ if $\frac{\partial \pi(k \tilde{\varepsilon}, s)}{\partial w_{0}}$ is increasing in $k$. These are indeed the cases by Lemma 2. The following Proposition concludes. 
Proposition 2a If preference exhibits DARA, risks are perfectly correlated and $k \geq$ 1 , then $F_{1}\left(S^{*}, d^{*}\right)>F_{1}(S, d)$ when agent 2 suffers from a sure reduction.

\subsection{An Increase in Risk}

Consider the situation where $\tilde{y}_{2}$ is replaced by $\tilde{y}_{2}^{*}=w_{0}+k^{*} \tilde{\varepsilon}$, with $k^{*}>k$. When risk is small with $\operatorname{Var}(\tilde{\varepsilon})=\sigma^{2}$, by applying Arrow-Pratt approximation, $C=2 w_{0}-$ $\left(\frac{1+k}{2}\right)^{2} A\left(w_{0}\right) \sigma^{2}, C^{*}=2 w_{0}-\delta_{0}-A\left(w_{0}\right)\left(\frac{1+k^{*}}{2}\right)^{2} \sigma^{2}, C_{2}^{d}=w_{0}-\frac{1}{2} A\left(w_{0}\right) k^{2} \sigma^{2}, C_{2}^{d *}=$ $w_{0}-\delta_{0}-\frac{1}{2} A\left(w_{0}\right) k^{* 2} \sigma^{2}$. Simple calculation gives

$$
\Delta C-\Delta C_{2}^{d}=-\frac{\left(2-k-k^{*}\right)\left(k^{*}-k\right)}{4} A\left(w_{0}\right) \sigma^{2},
$$

which is negative if $k \geq 1$. From Proposition 1 , DARA is sufficient to ensure that agent 1 betters off as agent 2's risk size increases.

In general, we have

$$
\Delta C=2\left(\pi\left(\frac{1+k^{*}}{2} \varepsilon, w_{0}\right)-\pi\left(\frac{1+k}{2} \varepsilon, w_{0}\right)\right)
$$

and

$$
\Delta C_{2}^{d}=\left(\pi\left(k^{*} \varepsilon, w_{0}\right)-\pi\left(k \varepsilon, w_{0}\right)\right)
$$

Hence,

$$
\begin{aligned}
\Delta C-\Delta C_{2}^{d} & =2\left(\pi\left(\frac{1+k^{*}}{2} \varepsilon, w_{0}\right)-\pi\left(\frac{1+k}{2} \varepsilon, w_{0}\right)\right)-\left(\pi\left(k^{*} \varepsilon, w_{0}\right)-\pi\left(k \varepsilon, w_{0}\right)\right) \\
& =2 \pi\left(\frac{1+k^{*}}{2} \varepsilon, w_{0}\right)-\pi\left(k^{*} \varepsilon, w_{0}\right)-\left(2 \pi\left(\frac{1+k}{2} \varepsilon, w_{0}\right)-\pi\left(k \varepsilon, w_{0}\right)\right)
\end{aligned}
$$

which is negative if $2 \pi\left(\frac{1+k}{2} \varepsilon, w_{0}\right)-\pi\left(k \varepsilon, w_{0}\right)$ decreases in $k$. Calculation gives

$$
\begin{aligned}
& \frac{\partial}{\partial k}\left(2 \pi\left(\frac{1+k}{2} \tilde{\varepsilon}, w_{0}\right)-\pi\left(k \tilde{\varepsilon}, w_{0}\right)\right) \\
& =\int_{\frac{1+k}{2}}^{k} \frac{\partial^{2} \pi\left(s \tilde{\varepsilon}, w_{0}\right)}{\partial k^{2}} d s,
\end{aligned}
$$

which is negative since $\frac{\partial^{2} \pi\left(s \tilde{\varepsilon}, w_{0}\right)}{\partial k^{2}}<0$ by Lemma 2 , if $k \geq 1$. Thus we have

Proposition $\mathbf{2 b}$ If preference exhibits DARA, risks are perfectly correlated and $k \geq$ 1 , then $F_{1}\left(S^{*}, d^{*}\right)>F_{1}(S, d)$ when agent 2's risk size increases. 


\section{Independent Risks}

Throughout this section, we assume that $\tilde{y}_{1}=w_{0}+\tilde{\varepsilon}_{1}, \tilde{y}_{2}=w_{0}+\tilde{\varepsilon}_{2}$, where $E\left(\tilde{\varepsilon}_{1}\right)=$ $E\left(\tilde{\varepsilon}_{2}\right)=0$ and $\tilde{\varepsilon}_{1}, \tilde{\varepsilon}_{2}$ are i.i.d. with support $[-a, a]$.

\subsection{A Sure Reduction}

Consider the situation where $\tilde{y}_{2}$ is replaced by $\tilde{y}_{2}^{*}=w_{0}-\delta_{0}+\tilde{\varepsilon}_{2}$, that is, agent 2 suffers from a sure reduction. When risk is small with $\operatorname{Var}(\tilde{\varepsilon})=\sigma^{2}$, by applying Arrow-Pratt approximation, we know that $C=2 w_{0}-\frac{1}{2} A\left(w_{0}\right) \sigma^{2}, C^{*}=2 w_{0}-\delta_{0}-\frac{1}{2} A\left(w_{0}-\frac{\delta_{0}}{2}\right) \sigma^{2}$, $C_{2}^{d}=w_{0}-\frac{1}{2} A\left(w_{0}\right) \sigma^{2}, C_{2}^{d *}=w_{0}-\delta_{0}-\frac{1}{2} A\left(w_{0}-\delta_{0}\right) \sigma^{2}$. Thus

$$
\Delta C-\Delta C_{2}^{d}=\frac{1}{2}\left(A\left(w_{0}-\frac{\delta_{0}}{2}\right)-A\left(w_{0}-\delta_{0}\right)\right) \sigma^{2},
$$

which is negative if preference satisfies DARA and positive if preference exhibits IARA. The following Proposition concludes.

Proposition 3a If risks are small and independent, and agent 2 suffers from a sure reduction, then $F_{1}\left(S^{*}, d^{*}\right)>F_{1}(S, d)$ if preference exhibits DARA, and $F_{1}\left(S^{*}, d^{*}\right)<F_{1}(S, d)$ if preference exhibits IARA.

In general,

$$
\begin{aligned}
& \Delta C=\delta_{0}-2\left(\pi\left(\frac{\tilde{\varepsilon}_{1}+\tilde{\varepsilon}_{2}}{2}, w_{0}\right)-\pi\left(\frac{\tilde{\varepsilon}_{1}+\tilde{\varepsilon}_{2}}{2}, w_{0}-\frac{\delta_{0}}{2}\right)\right) \\
& \Delta C_{2}^{d}=\delta_{0}-\left(\pi\left(\tilde{\varepsilon}_{2}, w_{0}\right)-\pi\left(\tilde{\varepsilon}_{2}, w_{0}-\delta_{0}\right)\right)
\end{aligned}
$$

From Lemma 2, we know that $\Delta C<\delta_{0}-\left(\pi\left(\frac{\tilde{\varepsilon}_{1}+\tilde{\varepsilon}_{2}}{2}, w_{0}\right)-\pi\left(\frac{\tilde{\varepsilon}_{1}+\tilde{\varepsilon}_{2}}{2}, w_{0}-\delta_{0}\right)\right)$. We will be done if the following inequality holds

$$
\pi\left(\frac{\tilde{\varepsilon}_{1}+\tilde{\varepsilon}_{2}}{2}, w_{0}-\delta_{0}\right)-\pi\left(\frac{\tilde{\varepsilon}_{1}+\tilde{\varepsilon}_{2}}{2}, w_{0}\right)<\pi\left(\tilde{\varepsilon}_{2}, w_{0}-\delta_{0}\right)-\pi\left(\tilde{\varepsilon}_{2}, w_{0}\right) .
$$

By the assumption that $\tilde{\varepsilon}_{1}$ and $\tilde{\varepsilon}_{2}$ are i.i.d., $\varepsilon_{2} \equiv \frac{\tilde{\varepsilon}_{1}+\tilde{\varepsilon}_{2}}{2}+\frac{\tilde{\varepsilon}_{1}-\tilde{\varepsilon}_{2}}{2}$ is a RothschildStiglitz increase in risk with respect to $\frac{\tilde{\varepsilon}_{1}+\tilde{\varepsilon}_{2}}{2}$ because

$$
E\left(\tilde{\varepsilon}_{1}-\tilde{\varepsilon}_{2} \mid \tilde{\varepsilon}_{1}+\tilde{\varepsilon}_{2}\right)=0 .
$$

Hence (8) can be interpreted as: the increased cost of risk associated with a sure reduction in wealth is smaller for less risky asset. Alternatively, one can also interprete 
equation (8) as the value of diversification: the increased cost of risk associated with a sure reduction in wealth is smaller for a more diversified asset. Before proceeding, we state the following Lemma.

Lemma 3 (8) holds if utility exhibits DARA in the sense of Ross on the interval $\left[w_{0}-a, w_{0}+a\right]$

Proof. Define $\Pi_{w_{0}}\left(\tilde{\varepsilon}_{2} \rightarrow \frac{\tilde{\varepsilon}_{1}+\tilde{\varepsilon}_{2}}{2}\right)$ as the monetary amount an agent is willing to pay to replace risk $\tilde{\varepsilon}_{2}$ with $\frac{\tilde{\varepsilon}_{1}+\tilde{\varepsilon}_{2}}{2}$ at initial position $w_{0}$. By definition,

$$
E u\left(w_{0}+\tilde{\varepsilon}_{2}\right)=E u\left(w_{0}-\Pi_{w_{0}}\left(\tilde{\varepsilon}_{2} \rightarrow \frac{\tilde{\varepsilon}_{1}+\tilde{\varepsilon}_{2}}{2}\right)+\frac{\tilde{\varepsilon}_{1}+\tilde{\varepsilon}_{2}}{2}\right)
$$

which can be rewritten as

$$
\begin{aligned}
& u\left(w_{0}-\pi\left(\tilde{\varepsilon}_{2}, w_{0}\right)\right) \\
= & u\left(w_{0}-\Pi_{w_{0}}\left(\tilde{\varepsilon}_{2} \rightarrow \frac{\tilde{\varepsilon}_{1}+\tilde{\varepsilon}_{2}}{2}\right)-\pi\left(\frac{\tilde{\varepsilon}_{1}+\tilde{\varepsilon}_{2}}{2}, w_{0}-\Pi_{w_{0}}\left(\tilde{\varepsilon}_{2} \rightarrow \frac{\tilde{\varepsilon}_{1}+\tilde{\varepsilon}_{2}}{2}\right)\right)\right)
\end{aligned}
$$

and thereby

$$
\pi\left(\tilde{\varepsilon}_{2}, w_{0}\right)=\Pi_{w_{0}}\left(\tilde{\varepsilon}_{2} \rightarrow \frac{\tilde{\varepsilon}_{1}+\tilde{\varepsilon}_{2}}{2}\right)+\pi\left(\frac{\tilde{\varepsilon}_{1}+\tilde{\varepsilon}_{2}}{2}, w_{0}-\Pi_{w_{0}}\left(\tilde{\varepsilon}_{2} \rightarrow \frac{\tilde{\varepsilon}_{1}+\tilde{\varepsilon}_{2}}{2}\right)\right)
$$

Substituting into the RHS of (8), we have

$$
\begin{aligned}
& \pi\left(\tilde{\varepsilon}_{2}, w_{0}-\delta_{0}\right)-\pi\left(\tilde{\varepsilon}_{2}, w_{0}\right) \\
= & \Pi_{w_{0}-\delta_{0}}\left(\tilde{\varepsilon}_{2} \rightarrow \frac{\tilde{\varepsilon}_{1}+\tilde{\varepsilon}_{2}}{2}\right)-\Pi_{w_{0}}\left(\tilde{\varepsilon}_{2} \rightarrow \frac{\tilde{\varepsilon}_{1}+\tilde{\varepsilon}_{2}}{2}\right) \\
+ & \pi\left(\frac{\tilde{\varepsilon}_{1}+\tilde{\varepsilon}_{2}}{2}, w_{0}-\delta_{0}-\Pi_{w_{0}-\delta_{0}}\left(\tilde{\varepsilon}_{2} \rightarrow \frac{\tilde{\varepsilon}_{1}+\tilde{\varepsilon}_{2}}{2}\right)\right)-\pi\left(\frac{\tilde{\varepsilon}_{1}+\tilde{\varepsilon}_{2}}{2}, w_{0}-\Pi_{w_{0}}\left(\tilde{\varepsilon}_{2} \rightarrow \frac{\tilde{\varepsilon}_{1}+\tilde{\varepsilon}_{2}}{2}\right)\right) \\
> & \pi\left(\frac{\tilde{\varepsilon}_{1}+\tilde{\varepsilon}_{2}}{2}, w_{0}-\delta_{0}-\Pi_{w_{0}-\delta_{0}}\left(\tilde{\varepsilon}_{2} \rightarrow \frac{\tilde{\varepsilon}_{1}+\tilde{\varepsilon}_{2}}{2}\right)\right)-\pi\left(\frac{\tilde{\varepsilon}_{1}+\tilde{\varepsilon}_{2}}{2}, w_{0}-\Pi_{w_{0}}\left(\tilde{\varepsilon}_{2} \rightarrow \frac{\tilde{\varepsilon}_{1}+\tilde{\varepsilon}_{2}}{2}\right)\right) \\
> & \pi\left(\frac{\tilde{\varepsilon}_{1}+\tilde{\varepsilon}_{2}}{2}, w_{0}-\delta_{0}-\Pi_{w_{0}}\left(\tilde{\varepsilon}_{2} \rightarrow \frac{\tilde{\varepsilon}_{1}+\tilde{\varepsilon}_{2}}{2}\right)\right)-\pi\left(\frac{\tilde{\varepsilon}_{1}+\tilde{\varepsilon}_{2}}{2}, w_{0}-\Pi_{w_{0}}\left(\tilde{\varepsilon}_{2} \rightarrow \frac{\tilde{\varepsilon}_{1}+\tilde{\varepsilon}_{2}}{2}\right)\right) \\
> & \pi\left(\frac{\tilde{\varepsilon}_{1}+\tilde{\varepsilon}_{2}}{2}, w_{0}-\delta_{0}\right)-\pi\left(\frac{\tilde{\varepsilon}_{1}+\tilde{\varepsilon}_{2}}{2}, w_{0}\right)
\end{aligned}
$$

The first inequality is due to the fact that $u$ is DARA in the sense of Ross and thereby $\Pi_{w_{0}-\delta_{0}}\left(\tilde{\varepsilon}_{2} \rightarrow \frac{\tilde{\varepsilon}_{1}+\tilde{\varepsilon}_{2}}{2}\right)>\Pi_{w_{0}}\left(\tilde{\varepsilon}_{2} \rightarrow \frac{\tilde{\varepsilon}_{1}+\tilde{\varepsilon}_{2}}{2}\right) .{ }^{4}$ The second inequality is due to the fact that $u$ is DARA in the sense of Arrow-Pratt and $\Pi_{w_{0}-\delta_{0}}\left(\tilde{\varepsilon}_{2} \rightarrow \frac{\tilde{\varepsilon}_{1}+\tilde{\varepsilon}_{2}}{2}\right)>$ $\Pi_{w_{0}}\left(\tilde{\varepsilon}_{2} \rightarrow \frac{\tilde{\varepsilon}_{1}+\tilde{\varepsilon}_{2}}{2}\right)$. The third inequality holds as $\pi$ is convex in $w_{0}$.

\footnotetext{
${ }^{4}$ Agent $u_{1}$ is ready to pay more than agent $u_{2}$ for any Rothschild-Stiglitz reduction in risk if and only if agent $u_{1}$ is more risk risk-averse than agent $u_{2}$ in the sense of Ross. (See Gollier 2001, Ch 7.3 , proposition 22.)
} 
It is yet to find the restrictions on utility function for DARA in the sense of Ross to hold. Following Eeckhoudt, Gollier and Schlesinger (1996), we know this is the case if there exists $\lambda$ such that

$$
\frac{-u^{\prime \prime \prime}\left(z_{0}\right)}{u^{\prime \prime}\left(z_{0}\right)} \geq \lambda \geq \frac{-u^{\prime \prime}(z)}{u^{\prime}(z)}, \forall z_{0}, z \in\left[w_{0}-a, w_{0}+a\right] .
$$

Under our assumption of HARA, i.e., $t(w) \triangleq-u^{\prime}(w) / u^{\prime \prime}(w)=\frac{1}{\gamma} w+\frac{1}{\alpha}$, the utility function can be written as $u(c)=\left(c+\frac{\gamma}{\alpha}\right)^{1-\gamma}$. Simple calculation shows that the above inequalities holds if

$$
a \leq \frac{\gamma+\alpha w_{0}}{2 \alpha \gamma+\alpha}
$$

i.e., the support of the risk is not too large.

Proposition 3b If preference exhibits DARA, risks are independent, the support of the risks are not too large,i.e., (9) holds, then $F_{1}\left(S^{*}, d^{*}\right)>F_{1}(S, d)$ when agent 2 suffers from a sure reduction.

\subsection{An Increase in Risk}

Consider the situation where $\tilde{y}_{2}$ is replaced by $\tilde{y}_{2}^{*}=w_{0}+\tilde{\varepsilon}_{2}^{*}$ such that the RothschildStiglitz (1970) increase in risk $\tilde{\varepsilon}_{2} \longrightarrow \tilde{\varepsilon}_{2}^{*}$ takes the form of adding independent noise. For small risk with $\operatorname{Var}\left(\tilde{\varepsilon}_{2}\right)=\sigma^{2}$ and $\operatorname{Var}\left(\tilde{\varepsilon}_{2}^{*}\right)=\sigma^{2 *}$, simple calculation yields:

$$
\Delta C-\Delta C_{2}^{d}=-\frac{1}{4} A\left(w_{0}\right)\left(\sigma^{2 *}-\sigma^{2}\right)<0,
$$

Consequently, DARA is sufficient to ensure agent 1 benefits from agent 2's deterioration.

In general,

$$
\begin{aligned}
& \Delta C_{2}^{d}=\pi\left(\tilde{\varepsilon}_{2}^{*}, w_{0}\right)-\pi\left(\tilde{\varepsilon}_{2}, w_{0}\right) \\
& \Delta C=2\left(\pi\left(\frac{\tilde{\varepsilon}_{1}+\tilde{\varepsilon}_{2}^{*}}{2}, w_{0}\right)-\pi\left(\frac{\tilde{\varepsilon}_{1}+\tilde{\varepsilon}_{2}}{2}, w_{0}\right)\right)
\end{aligned}
$$

Hence, $\Delta C<\Delta C_{2}^{d}$ iff

$$
\pi\left(\tilde{\varepsilon}_{2}^{*}, w_{0}\right)-\pi\left(\tilde{\varepsilon}_{2}, w_{0}\right)>2\left(\pi\left(\frac{\tilde{\varepsilon}_{1}+\tilde{\varepsilon}_{2}^{*}}{2}, w_{0}\right)-\pi\left(\frac{\tilde{\varepsilon}_{1}+\tilde{\varepsilon}_{2}}{2}, w_{0}\right)\right)
$$

The inequality reflects the value of risk sharing. It says the increased cost of risk associated with a deterioration in agent 2's income is smaller in the presence 
of risk sharing. As an illustration, suppose agent 2's income deteriotates. Without agent 1 to share the risk, the cost of the risk of agent 2 increased by $€ 10$. With agent 1 to share the risk, each agent bears only half of the deterioration. The cost of the risk of each agent increased only by $€ 4$. The total increased cost of the risk is $2 \times € 4=€ 8<€ 10$.

Lemma 4 If Rothschild-Stiglitz increase in risk $\tilde{\varepsilon}_{2} \longrightarrow \tilde{\varepsilon}_{2}^{*}$ takes the form of adding independent noise and utility exhibits DARA in the sense of Ross on the interval $\left[w_{0}-a, w_{0}+a\right]$, then (11) holds.

Proof. Suppose $\tilde{\varepsilon}_{2}^{*}={ }_{d} \tilde{\varepsilon}_{2}+\tilde{\eta}$, where $\tilde{\varepsilon}_{2}$ and $\tilde{\eta}$ are independent. We prove the following two inequalities

$$
\begin{gathered}
\pi\left(\tilde{\varepsilon}_{2}+\tilde{\eta}, w_{0}\right)-\pi\left(\tilde{\varepsilon}_{2}, w_{0}\right)>\pi\left(\frac{\tilde{\varepsilon}_{1}+\tilde{\varepsilon}_{2}}{2}+\tilde{\eta}, w_{0}\right)-\pi\left(\frac{\tilde{\varepsilon}_{1}+\tilde{\varepsilon}_{2}}{2}, w_{0}\right) \\
\pi\left(\frac{\tilde{\varepsilon}_{1}+\tilde{\varepsilon}_{2}}{2}+\tilde{\eta}, w_{0}\right)-\pi\left(\frac{\tilde{\varepsilon}_{1}+\tilde{\varepsilon}_{2}}{2}, w_{0}\right)>2\left(\pi\left(\frac{\tilde{\varepsilon}_{1}+\tilde{\varepsilon}_{2}+\tilde{\eta}}{2}, w_{0}\right)-\pi\left(\frac{\tilde{\varepsilon}_{1}+\tilde{\varepsilon}_{2}}{2}, w_{0}\right)\right)
\end{gathered}
$$

(12) says that the increased cost of risk associated with adding an independent white noise is smaller for a more diversified asset. Rewrite (12) as

$$
\pi\left(\tilde{\varepsilon}_{2}+\tilde{\eta}, w_{0}\right)-\pi\left(\frac{\tilde{\varepsilon}_{1}+\tilde{\varepsilon}_{2}}{2}+\tilde{\eta}, w_{0}\right)>\pi\left(\tilde{\varepsilon}_{2}, w_{0}\right)-\pi\left(\frac{\tilde{\varepsilon}_{1}+\tilde{\varepsilon}_{2}}{2}, w_{0}\right)
$$

where

$$
\begin{aligned}
& \pi\left(\tilde{\varepsilon}_{2}+\tilde{\eta}, w_{0}\right)-\pi\left(\frac{\tilde{\varepsilon}_{1}+\tilde{\varepsilon}_{2}}{2}+\tilde{\eta}, w_{0}\right) \\
= & \Pi_{w_{0}}\left(\tilde{\varepsilon}_{2}+\tilde{\eta} \rightarrow \tilde{\varepsilon}_{2}\right)-\Pi_{w_{0}}\left(\frac{\tilde{\varepsilon}_{1}+\tilde{\varepsilon}_{2}}{2}+\tilde{\eta} \rightarrow \frac{\tilde{\varepsilon}_{1}+\tilde{\varepsilon}_{2}}{2}\right) \\
+ & \pi\left(\tilde{\varepsilon}_{2}, w_{0}-\Pi_{w_{0}}\left(\tilde{\varepsilon}_{2}+\tilde{\eta} \rightarrow \tilde{\varepsilon}_{2}\right)\right)-\pi\left(\frac{\tilde{\varepsilon}_{1}+\tilde{\varepsilon}_{2}}{2}, w_{0}-\Pi_{w_{0}}\left(\frac{\tilde{\varepsilon}_{1}+\tilde{\varepsilon}_{2}}{2}+\tilde{\eta} \rightarrow \frac{\tilde{\varepsilon}_{1}+\tilde{\varepsilon}_{2}}{2}\right)\right) \\
> & \pi\left(\tilde{\varepsilon}_{2}, w_{0}-\Pi_{w_{0}}\left(\tilde{\varepsilon}_{2}+\tilde{\eta} \rightarrow \tilde{\varepsilon}_{2}\right)\right)-\pi\left(\frac{\tilde{\varepsilon}_{1}+\tilde{\varepsilon}_{2}}{2}, w_{0}-\Pi_{w_{0}}\left(\frac{\tilde{\varepsilon}_{1}+\tilde{\varepsilon}_{2}}{2}+\tilde{\eta} \rightarrow \frac{\tilde{\varepsilon}_{1}+\tilde{\varepsilon}_{2}}{2}\right)\right) \\
> & \pi\left(\tilde{\varepsilon}_{2}, w_{0}-\Pi_{w_{0}}\left(\tilde{\varepsilon}_{2}+\tilde{\eta} \rightarrow \tilde{\varepsilon}_{2}\right)\right)-\pi\left(\frac{\tilde{\varepsilon}_{1}+\tilde{\varepsilon}_{2}}{2}, w_{0}-\Pi_{w_{0}}\left(\tilde{\varepsilon}_{2}+\tilde{\eta} \rightarrow \tilde{\varepsilon}_{2}\right)\right) \\
> & \pi\left(\tilde{\varepsilon}_{2}, w_{0}\right)-\pi\left(\frac{\tilde{\varepsilon}_{1}+\tilde{\varepsilon}_{2}}{2}, w_{0}\right)
\end{aligned}
$$

Notice that $\Pi_{w_{0}}\left(\tilde{\varepsilon}_{2}+\tilde{\eta} \rightarrow \tilde{\varepsilon}_{2}\right)$ is equivalent to the risk premium of $\tilde{\eta}$ in the presence of independent background risk $\tilde{\varepsilon}_{2}$ while $\Pi_{w_{0}}\left(\frac{\tilde{\varepsilon}_{1}+\tilde{\varepsilon}_{2}}{2}+\tilde{\eta} \rightarrow \frac{\tilde{\varepsilon}_{1}+\tilde{\varepsilon}_{2}}{2}\right)$ is equivalent to the risk premium of $\tilde{\eta}$ in the presence of independent background risk $\frac{\tilde{\varepsilon}_{1}+\tilde{\varepsilon}_{2}}{2}$. Eeckhoudt, Gollier and Schlesinger (1996) has proved that, under decreasing absolute prudence, any SSD deterioration in background risk raises risk aversion if absolute aversion is decreasing in the sense of Ross over the relevant range of wealth. While the risk tolerance is linear, it's easy to show that the absolute prudence is decreasing. The 
inequality $\Pi_{w_{0}}\left(\tilde{\varepsilon}_{2}+\tilde{\eta} \rightarrow \tilde{\varepsilon}_{2}\right)>\Pi_{w_{0}}\left(\frac{\tilde{\varepsilon}_{1}+\tilde{\varepsilon}_{2}}{2}+\tilde{\eta} \rightarrow \frac{\tilde{\varepsilon}_{1}+\tilde{\varepsilon}_{2}}{2}\right)$ and therefore the first inequality holds because of the facts that i) $\frac{\tilde{\varepsilon}_{1}+\tilde{\varepsilon}_{2}}{2}$ second-order stochastically dominates $\tilde{\varepsilon}_{2}$; ii) utility satisfies DARA in the sense of Ross; iii) risk tolerance is linear by assumption. The second inequality is due to DARA. The last inequality is due to (8). Inequality (13) can be rewritten as

$$
\pi\left(\frac{\tilde{\varepsilon}_{1}+\tilde{\varepsilon}_{2}}{2}+\tilde{\eta}, w_{0}\right)+\pi\left(\frac{\tilde{\varepsilon}_{1}+\tilde{\varepsilon}_{2}}{2}, w_{0}\right)>2 \pi\left(\frac{\tilde{\varepsilon}_{1}+\tilde{\varepsilon}_{2}+\tilde{\eta}}{2}, w_{0}\right),
$$

which holds if $\pi\left(\frac{\tilde{\varepsilon}_{1}+\tilde{\varepsilon}_{2}}{2}+k \tilde{\eta}, w_{0}\right)$ is convex in $k$. Using similar method as in proof of Lemma 2, we can easily show that this is indeed the case. Combining (12) and (13) we get (11).

Proposition 3c If preference exhibits DARA, risks are independent, the support of the risks are not too large, i.e., (9) holds, then $F_{1}\left(S^{*}, d^{*}\right)>F_{1}(S, d)$ when agent 2's income suffers from an additional independent noise

Notice that $\tilde{\varepsilon}_{1}$ and $\tilde{\varepsilon}_{2}$ do not have to be identically distributed for the above results to hold. The key assumption here is that $\tilde{\varepsilon}_{2}$ is an increase in risk with respect to $\frac{\tilde{\varepsilon}_{1}+\tilde{\varepsilon}_{2}}{2}$. In other words, all the above predictions hold if $E\left(\tilde{\varepsilon}_{1}-\tilde{\varepsilon}_{2} \mid \tilde{\varepsilon}_{1}+\tilde{\varepsilon}_{2}\right) \leq 0$. If this is not the case, we may have opposite prediction as shown in Example 1: a deterioration in one bargainer's position is more likely to hurt his opponent if his initial risk is sufficiently small $\left(\tilde{\varepsilon}_{2} \rightarrow 0\right)$.

\section{Application: Matching to Share Risk}

Consider a risk-sharing matching game with $N$ males $\left\{m_{i} ; i=1, \ldots, N\right\}$ on one side and $N$ females $\left\{f_{j} ; j=1, \ldots, N\right\}$ on the other side. All agents are expected utility maximizers with respect to homogeneous probabilistic belief, and have identical HARA vNM utility function $u$.

Agents have the opportunity to form marriages for sharing earning-risks. The timing of the matching game goes as follows:

1) Every male proposes to his most preferred female;

2) The female chooses among all the suitors her most favorable man as her Mr. Right, and turns down the others; 
3) Upon getting married, the couple will commit to a rule for sharing their pooled income in each state of the world according to Nash Bargaining solution, with their threat points being consuming his/her own income;

4) The remaining males propose to the remaining females as in stage 1).

Notice that an agent's fall-back position is to consume his's own income. Hence we implicitly rule out the possibility of remarriage, which is a reasonable assumption if divorce is too costly, either physically or psychologically. Allowing for remarriage makes a different story and we leave it for future work.

Scenario 1. All agents face identically distributed risks, either perfect correlated or independent. Within each side of the population, agents can be ranked according to their initial wealth. Assume $w_{1}^{i}<w_{2}^{i}<\cdots<w_{N}^{i}, i=m, f$, where $w_{n}^{m}$ is male $n$ 's initial wealth and $w_{n}^{f}$ is female $n$ 's initial wealth.

Scenario 2. All agents have the same initial wealth but differ in their income riskiness: $\varepsilon_{1}^{i} \succ \varepsilon_{2}^{i} \cdots \succ \varepsilon_{N}^{i}$. Moreover, assume $\varepsilon_{n}^{m}$ and $\varepsilon_{n}^{f}$ are identically distributed.

In both scenarios, by Proposition 2 and Proposition 3, all males prefer and hence propose to female 1 , while female 1 will accept to marry to male 1 . Similar logic applies to the remaining population. Consequently, we have:

Proposition 4 The matching pattern is positive assortative: male $n$ marries to female $n$. In scenario 1 , rich marrying rich, poor marrying poor. In scenario 2 , risky marrying risky, riskless marrying riskless.

The above prediction is consistent with empirical findings in household economics. For example, marriages are sorted positively in education and wages (Becker 1973, 1974; Lam 1988), factors that determine the wealth and riskiness of individual income. Among the same crowed of people with the same type of job and same level of education, we see indicators that sorting is positive in wealth. Charles and Hurst (2003) have found from PSID data that parent's wealth of husband and wife are positively correlated. Understanding the matching pattern of marriage is important since it has significant impact on the family's decision such as human capital investments, especially investments in descendants. (We refer to Ludo Visschers, "a note on search and assortative matching in wealth" for a discussion). 


\section{Robustness}

\subsection{The Rubinstein Bargaining Solution}

In parallel to the axiomatic models, Rubinstein (1982) developed a strategic model of multiperiod bargaining. In this section, we will show that our result is robust under Rubinstein's alternating-offer bargaining game. Consider an infinite horizon game in which two agents live for infinite periods. They receive income $\tilde{y}_{1 t}, \tilde{y}_{2 t}$ at each periods. Assume that $\tilde{y}_{i t_{1}}$ and $\tilde{y}_{i t_{2}}$ are i.i.d., $\forall t_{1}, t_{2}$ and $i=1,2$. In any period (before the realization of the risky income), one agent has the option to propose a risk sharing rule, and the other agent has the option to accept or reject it. At any period in which an offer is accept, the two agents commit to the risk sharing rule for all the remaining periods. After any period in which an offer is rejected, two agents consume their own income in that period and the game continues for another period, in which the option to make an offer on risk sharing rule switches to the other player.

Notice that there are two implicit assumptions in this game. First, there is no saving and therefore both agents consume all their income in each period. Second, once an agreement is reached, both agents will commit to it. This assumption can be justified under the assumption of infinite horizon, as long as the maximum realization of income is finite and both agents are sufficiently patient. Indeed, the cooperative behavior can be sustained as a subgame perfect equilibrium if both agents adopt the trigger strategy, e.g., grim trigger or tit-for-tat.

Under the assumption of HARA, offering risk sharing rule is equivalent to offering how to share the total certainty equivalence at each state of the world. Define $N C=$ $C-C_{1}^{d}-C_{2}^{d}$ as the net certainty equivalence created by risk sharing. Agent i's offer is denoted by $\left(a_{i}, N C-a_{i}\right)$, where $a_{i}$ is the share that agent 1 can get from $N C$. If the agreement $(a, N C-a)$ is reached at time $T$, then agent 1 's utility is

$$
\begin{aligned}
& \sum_{t=0}^{T-1} \delta^{t} u\left(C_{1}^{d}\right)+\sum_{t=T}^{\infty} \delta^{t} u\left(C_{1}^{d}+a\right) \\
= & \sum_{t=0}^{T-1} \delta^{t} u\left(C_{1}^{d}\right)+\frac{\delta^{T}}{1-\delta} u\left(C_{1}^{d}+a\right)
\end{aligned}
$$


and agent 2's utility is

$$
\begin{aligned}
& \sum_{t=0}^{T-1} \delta^{t} u\left(C_{2}^{d}\right)+\sum_{t=T}^{\infty} \delta^{t} u\left(C_{2}^{d}+N C-a\right) \\
= & \sum_{t=0}^{T-1} \delta^{t} u\left(C_{2}^{d}\right)+\frac{\delta^{T}}{1-\delta} u\left(C_{2}^{d}+N C-a\right)
\end{aligned}
$$

Rubinstein (1982) proves the existence and uniqueness of subgame perfect equilibrium of such bargaining game. In equilibrium, when it is agent 1's turn to offer he always offers agent 2 the agreement $\left(a_{1}^{e}, N C-a_{1}^{e}\right)$ which makes agent 2 indifferent between agreeing and waiting until next period for her turn to make offer. Similarly agent 2 always offers the agreement $\left(a_{2}^{e}, N C-a_{2}^{e}\right)$ that makes agent 1 indifferent between agreeing now and waiting. Thus the equilibrium $a_{1}^{e}$ and $a_{2}^{e}$ are the solution to the following equations combined:

$$
\begin{aligned}
\frac{1}{1-\delta} u\left(C_{2}^{d}+N C-a_{1}\right) & =u\left(C_{2}^{d}\right)+\frac{\delta}{1-\delta} u\left(C_{2}^{d}+N C-a_{2}\right) \\
\frac{1}{1-\delta} u\left(C_{1}^{d}+a_{2}\right) & =u\left(C_{1}^{d}\right)+\frac{\delta}{1-\delta} u\left(C_{1}^{d}+a_{1}\right)
\end{aligned}
$$

where the LHS is what an agent can get by agreeing immediately and the RHS is what an agent can get by waiting.

Define $v_{1}(x)=u\left(C_{1}^{d}+x\right)-u\left(C_{1}^{d}\right)$ and $v_{2}(x)=u\left(C_{2}^{d}+x\right)-u\left(C_{2}^{d}\right)$, then the above equation becomes

$$
\begin{aligned}
v_{2}\left(N C-a_{1}\right) & =\delta v_{2}\left(N C-a_{2}\right) \\
v_{1}\left(a_{2}\right) & =\delta v_{1}\left(a_{1}\right) .
\end{aligned}
$$

Notice that $v_{i}(0) i=0, v_{i}^{\prime}(x)=u^{\prime}\left(C_{i}^{d}+x\right)$ and $v_{i}^{\prime \prime}(x)=u^{\prime \prime}\left(C_{i}^{d}+x\right), i=1,2$. Moreover, from (15), we know $v_{1}\left(a_{2}\right)<v_{1}\left(a_{1}\right)$ and hence, by $v_{1}^{\prime}(x)>0$, we have $a_{1}>a_{2}$ : agent 1 always proposes a higher share for himself than agent 2 does for agent 1 .

Equation (15) gives a function $a_{1}=f_{1}\left(a_{2}\right)$ and equation (14) gives a function $a_{1}=f_{2}\left(a_{2}\right)$. Then, $f_{2}(N C)=N C$ and $v_{1}(N C)=\delta v_{1}\left(f_{1}(N C)\right)<v_{1}\left(f_{1}(N C)\right) \Rightarrow$ $f_{1}(N C)>N C=f_{2}(N C)$. Similarly, $f_{1}(0)=0$ and $v_{2}\left(N C-f_{2}(0)\right)=\delta v_{2}(N C)<$ $v_{2}(N C) \Rightarrow f_{2}(0)>0=f_{1}(0)$. Moreover,

$$
\begin{aligned}
& 0<f_{2}^{\prime}\left(a_{2}\right)=\frac{\delta v_{2}^{\prime}\left(N C-a_{2}\right)}{v_{2}^{\prime}\left(N C-a_{1}\right)} \\
&<\frac{v_{1}^{\prime}\left(a_{2}\right)}{\delta v_{1}^{\prime}\left(a_{1}\right)}=f_{1}^{\prime}\left(a_{2}\right) .
\end{aligned}
$$


The last inequality is due to the facts that $a_{1}>a_{2} \Rightarrow \frac{v_{2}^{\prime}\left(N C-a_{2}\right)}{v_{2}^{\prime}\left(N C-a_{1}\right)}<1$ and $\frac{v_{1}^{\prime}\left(a_{2}\right)}{\delta v_{1}^{\prime}\left(a_{1}\right)}>1$. The above analysis show that $f_{1}\left(a_{2}\right)$ crosses $f_{2}\left(a_{2}\right)$ from below.

Lemma 5 If $v_{2}$ is changing to a new function $\widetilde{v}_{2}$ with $\frac{-\widetilde{v}_{2}^{\prime \prime}}{\widetilde{v}_{2}^{\prime}}>\frac{-v_{2}^{\prime \prime}}{v_{2}^{\prime}}$, i.e., agent 2 becomes more risk-averse, and $v_{2}(0)=\widetilde{v}_{2}(0)=0$, then the corresponding $\widetilde{f}_{2}\left(a_{2}\right)>f_{2}\left(a_{2}\right)$.

Proof. See appendix.

Figure 1 illustrates how the equilibrium proposal changes when agent 2 becomes more risk averse.

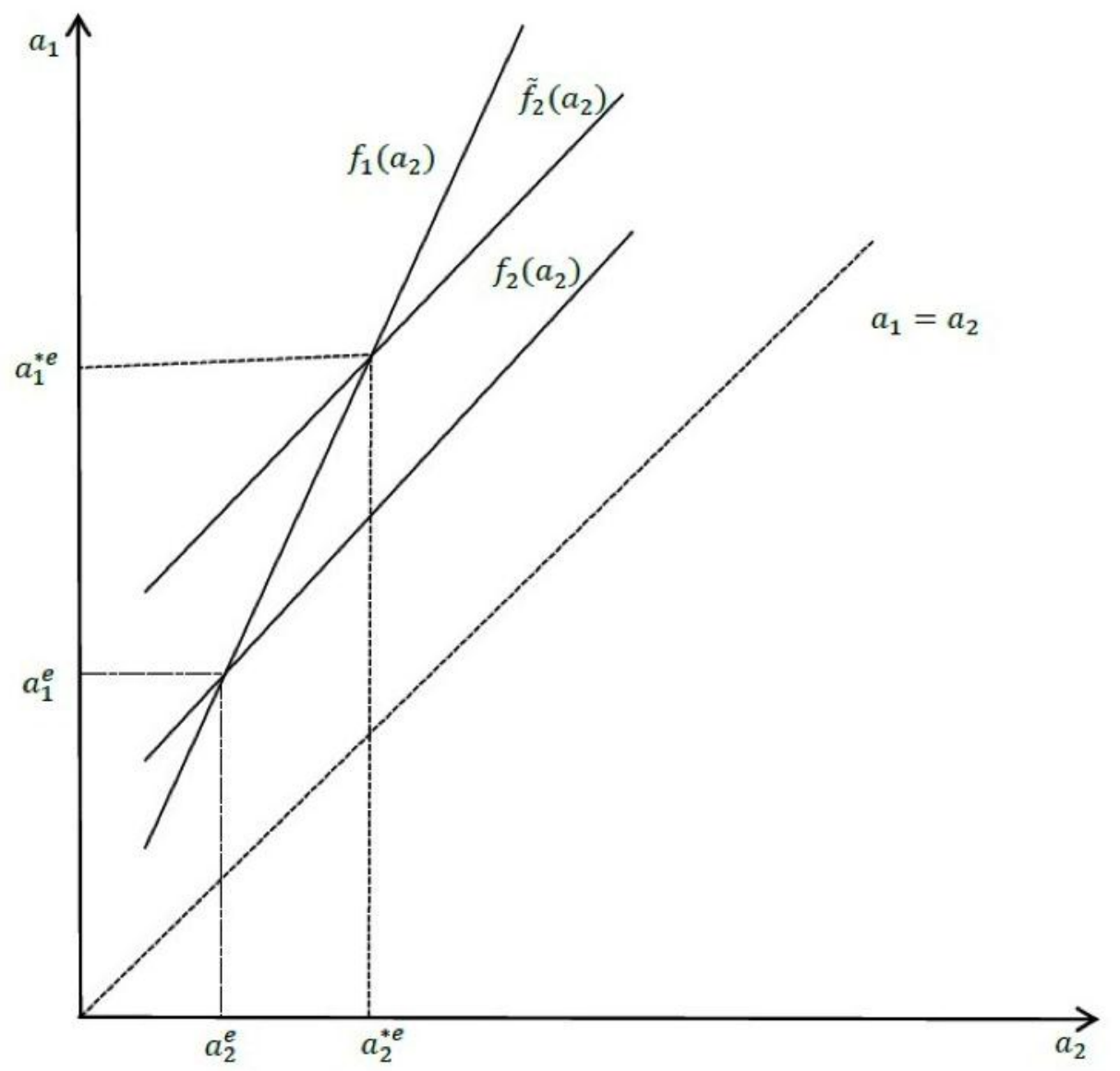

As is apparent from the figure, in Rubinstein's bargaining model of risk sharing, agent 1 will be better off if agent 2 becomes more risk-averse: $a_{i}^{* e}>a_{i}^{e}$.

From (14), we also know that

$$
\frac{\partial f_{2}\left(a_{2}\right)}{\partial N C}=\frac{v_{2}^{\prime}\left(N C-a_{1}\right)-\delta v_{2}^{\prime}\left(N C-a_{2}\right)}{v_{2}^{\prime}\left(N C-a_{1}\right)}>0
$$


Hence, increasing $N C$ shifts the curve $a_{1}=f_{2}\left(a_{2}\right)$ upward.

Now we are ready to state the comparative statics regarding a deterioration in the agent 2's income. Let $\tilde{y}_{2}^{*}$ denote agent 2's random prospect after the deterioration. As before, denote $\Delta C=C-C^{*}$ and $\Delta C_{2}^{d}=C_{2}^{d}-C_{2}^{d *}$. Moreover, denote $\left(a_{i}^{* e}, N C-a_{i}^{* e}\right)$ the equilibrium offer after the deterioration.

Proposition 5 If preference exhibits DARA and $\Delta C<\Delta C_{2}^{d}$, then $a_{1}^{* e}>a_{1}^{e}$; if preference exhibits IARA and $\Delta C>\Delta C_{2}^{d}$, then $a_{1}^{* e}<a_{1}^{e}$.

Proof. $a_{1}^{* e}$ and $a_{2}^{* e}$ are jointly determined by equation (15) and

$$
\widetilde{v}_{2}\left(N C+\Delta C-\Delta C_{2}^{d}-a_{1}\right)=\delta \widetilde{v}_{2}\left(N C+\Delta C-\Delta C_{2}^{d}-a_{2}\right),
$$

where $\widetilde{v}_{2}(x)=u\left(C_{2}^{d *}+x\right)-u\left(C_{2}^{d *}\right)$. Notice $\widetilde{v}_{2}(x)=0$. The above equation gives a function $a_{1}=f_{2}^{*}\left(a_{2}\right)$. By Lemma 5 and the fact that $\frac{\partial f_{2}\left(a_{2}\right)}{\partial N C}>0$, we know the curve $f_{2}$ is shifting upward: $f_{2}^{*}\left(a_{2}\right)>f_{2}\left(a_{2}\right)$ if preference exhibit DARA and $\Delta C<\Delta C_{2}^{d}$. Since the curve $f_{1}\left(a_{2}\right)$ remains unchanged and the curves $f_{2}\left(a_{2}\right)$ and $f_{2}^{*}\left(a_{2}\right)$ cross it from above, and that $f_{i}^{\prime}\left(a_{2}\right)>0$ for $i=1,2$, we have $a_{1}^{* e}>a_{1}^{e}$. See figure 1 for an illustration. Similarly, when preference exhibit DARA and $\Delta C>\Delta C_{2}^{d}$ we have $f_{2}^{*}\left(a_{2}\right)<f_{2}\left(a_{2}\right)$ and hence $a_{1}^{* e}<a_{1}^{e}$.

Proposition 5 says that our result is robust in the strategic bargaining game. Under DARA, a deterioration makes agent 2 more risk averse and thus in a disadvantageous position in the noncooperative game. As a result, agent 1's share of the net certainty equivalence increases. As long as the size of the net certainty equivalent is non-decreasing under the deterioration, he will be strictly better off. It shows that the comparative statics prediction of the axiomatic model is preserved in the strategic model.

\subsection{Positive $B$}

In this section, we check the previously derived sufficient conditions which guarantee that $\Delta C-\Delta C_{2}^{d}<0$ for $B=0$ also guarantee $\Delta C-\Delta C_{2}^{d}<0$ for $B>0$. This will be the case if $\Delta C$ is decreasing in $B$, as $\Delta C_{2}^{d}$ does not change with $B$. For the case of perfectly correlated risk and a sure reduction, by (5), we have

$$
\Delta C=\delta_{0}+2\left(\pi\left(\frac{1+k}{2} \tilde{\varepsilon}, w_{0}+\frac{B}{2}-\frac{\delta_{0}}{2}\right)-\pi\left(\frac{1+k}{2} \tilde{\varepsilon}, w_{0}+\frac{B}{2}\right)\right),
$$


which, by the fact that $\pi\left(\frac{1+k}{2} \tilde{\varepsilon}, w_{0}\right)$ is convex in $w_{0}$, is indeed decreasing in $B$.

For the case of perfectly correlated risk and an increase in risk, by (6), we have

$$
\Delta C=2\left(\pi\left(\frac{1+k^{*}}{2} \tilde{\varepsilon}, w_{0}+\frac{B}{2}\right)-\pi\left(\frac{1+k}{2} \tilde{\varepsilon}, w_{0}+\frac{B}{2}\right)\right)
$$

which, by the fact that $\frac{\partial^{2}}{\partial k \partial w_{0}} \pi\left(\frac{1+k}{2} \tilde{\varepsilon}, w_{0}\right) \leq 0$ (See appendix for a proof), is indeed decreasing in $B$.

For the case of independent risk and a sure reduction, , by (7), we can see the proof that $\Delta C$ is decreasing in $B$ is exactly the same as in the case of perfect correlated risk and a sure reduction.

For the case of independent risk and an increase in risk, , by (5), we know that $\Delta C$ decreasing in $B$ is equivalent to

$$
\frac{\partial}{\partial w_{0}}\left[\pi\left(\frac{\tilde{\varepsilon}_{1}+\tilde{\varepsilon}_{2}^{*}}{2}, w_{0}\right)-\frac{\partial}{\partial w_{0}} \pi\left(\frac{\tilde{\varepsilon}_{1}+\tilde{\varepsilon}_{2}}{2}, w_{0}\right)\right] \leq 0,
$$

where $\tilde{\varepsilon}_{2}^{*}=\tilde{\varepsilon}_{2}+\tilde{\eta}$, with $\tilde{\eta}$ independent of $\varepsilon_{i}$ s. Using similar method as in proof of Lemma 3, we can derive that the above inequality holds if $\Pi_{w_{0}}\left(\frac{\tilde{\varepsilon}_{1}+\tilde{\varepsilon}_{2}}{2}+\frac{\tilde{\eta}}{2} \rightarrow \frac{\tilde{\varepsilon}_{1}+\tilde{\varepsilon}_{2}}{2}\right)$, which represents the risk premium of $\frac{\tilde{\eta}}{2}$ in the presence of independent background risk $\frac{\tilde{\varepsilon}_{1}+\tilde{\varepsilon}_{2}}{2}$, is decreasing in $w_{0}$. By Gollier (2001), we know the property of DARA is preserved in the presence of independent background risk and hence $\Pi_{w_{0}}\left(\frac{\tilde{\varepsilon}_{1}+\tilde{\varepsilon}_{2}}{2}+\frac{\tilde{\eta}}{2} \rightarrow \frac{\tilde{\varepsilon}_{1}+\tilde{\varepsilon}_{2}}{2}\right)$ is indeed decreasing in $w_{0}$.

\section{Concluding Remarks}

When bargaining situation concerns risky outcomes and risky disagreement points, we show that, under linear risk tolerance, bargaining solution can be viewed as division of a fixed amount of monetary equivalent between two risk-averse agents. That is, monetary equivalent can be losslessly transferred from one bargainer to the other bargainer. Thus whether a deterioration of a bargainer's risky prospect benefits his opponent depends on the net effect on the total bargaining surplus. Our findings enrich the game-theoretic bargaining literature concerning stochastic outcomes and disagreement points, and to the best of our knowledge, are the first attempt to examine comparative statics regarding sure reduction and Rothschild-Stiglitz increase in risk. 
The present research can be extended along two lines. Firstly, in addition to Nash's and Rubinstein's solution, a number of other social division rules can be examined, which may include the Kalai-Smorodinsky solution, the Egalitarian solution and the Equal Sacrifice solution. Secondly, the current results are obtained within transferable utility games. Other than the HARA preferences, the efficient risk sharing rule which maps household joint income into individual consumption is typically nonlinear. It is, however, worthwhile to find less sufficient restrictions on utility other than linear tolerance for the current predictions to hold.

\section{References}

[1] Arrow, K. J., (1971), "Uncertainty and the Welfare Economics of Medical Care," in his Essays in the Theory of Risk-Bearing, Chicago

[2] Ayalew, D., (2003), "Risk-sharing Networks among Households in Rural Ethiopia," Working Paper 2003-4, CSAE, Oxford University.

[3] Becker, G., (1973), "A Theory of Marriage: Part I," Journal of Political Economy $81(4), 813-846$

[4] — (1974), "A Theory of Marriage: Part II," Journal of Political Economy $82(2$, part 2), S11-S26

[5] Charles, K. and Hurst, E., (2003), "The Correlation of Wealth Across Generations," Journal of Political Economy, v111 (6, Dec), 1155-1182.

[6] Eeckhoudt, L. and Gollier, C., (2001), "Which Shape for the Cost Curve of Risk," The Journal of Risk and Insurance, vol. 68, No. 3, 387-401

[7] Fafchamps, M. and Lund, S., (2003), "Risk Sharing Networks in Rural Philippines," Journal of Development Economics, 71:261-287

[8] Gollier, C. (2001), The Economics of Risk and Time, Cambridge,. MA: The MIT Press

[9] Gollier, C. and Pratt, J. W., (1996), "Risk Vulnerability and the Tempering Effect of Background Risk," Econometrica, vol. 64, No. 5, 1109-1123

[10] Hess, G. D., (2004), "Marriage and Consumption Insurance: What's Love Got to Do with It?" Journal of Political Economy 112 (2), 290-318. 
[11] Kalai, E. and Smorodinsky, M., (1975), "The Solutions to Nash's Bargaining Problem," Econometrica, 43, 513-518.

[12] Kannai, Y., (1977), "Concavifiability and Constructions of Concave Utility Functions," Journal of Mathematical Economics, 4, 1-56.

[13] Kihlstrom, R. A., Roth, A. E. and Schmeidler, D., (1981), "Risk Aversion and Solutions to Nash's Bargaining Problem," In: O. Moeschlin, and D. Pellascke, eds. Game Theory and Mathematical Economics, Amsterdam: North Holland, $65-71$

[14] Kotlikoff, L. and Spivak, A., (1981), "The family as an incomplete annuity market," Journal of Political Economy, 89: 372-391.

[15] Lam, D., (1988), "Marriage Markets and Assortative Mating with Household Public Goods: Theoretical Results and Empirical Implications," Journal of Human Resources, 23:462-487

[16] Ligon, E., J. P. Thomas, and Worrall, T., (2002), "Mutual Insurance and Limited Commitment: Theory and Evidence in Village Economies," Review of Economic Studies, 69, 115-139.

[17] Nash, J. F., (1950), "The Bargaining Problem," Econometrica, 28, 155-162.

[18] Perles, M. A. and Maschler, M., (1981), "The Super-Additive Solution for the Nash Bargaining Game," International Journal of Game Theory, 10, 163-93

[19] Pollack, R. A., (1985) "A Transaction Cost Approach to Families and Households," Journal of Economic Literature, XXIII, June pp.581-608

[20] Riddell, W. C., (1981), "Bargaining under Uncertainty," American Economic Review, Vol. 71, No. 4, 579-590

[21] Rosenzweig, M., (1988), "Risk, Implicit Contracts and the Family in Rural Areas of Low Income Countries," Economic Journal, 98 (December 1988): 1148-70

[22] Rosenzweig, M. and Stark, O., (1989), "Consumption smoothing, migration, and marriage: evidence from rural India," Journal of Political Economy, 97: 905-926.

[23] Ross, S. A., (1981), "Some Stronger Measures of Risk Aversion in the Small and in the Large with Applications," Econometrica, 3, 621-638 
[24] Roth, A. E., (1977), "The Shapley Value as a Von Neumann-Morgenstem Utility Function," Econometrica, 45, 657-664.

[25] Roth, A. E., (1978), "The Nash Solution and the Utility of Bargaining," Econometrica, 46, 587-594.

[26] Roth, A. E., (1979), Axiomatic Models of Bargaining, Berlin: Springer

[27] Roth, A. E., (1985), "A Note on Risk Aversion in A Perfect Equilibrium Model of Bargaining," Econometrica, 53, 207-211.

[28] Roth, A. E., (1985b), "Towards a Focal-Point Theory of Bargaining," In: A. E. Roth, ed., Game Theoretic Models of Bargaining, Cambridge University Press, $259-268$

[29] Roth, A. E., (1989), "Risk Aversion and The Relation between Nash's Solution and Subgame Perfect Equilibrium of Sequential Bargaining," Journal of Risk and Uncertainty, 2, 353-365.

[30] Roth, A. E. and Rothblum, U., (1982), "Risk Aversion and Nash's Solution for Bargaining Games with Risky Outcomes," Econometrica 50, 639-647.

[31] Rothschild, M. and Stiglitz, J., (1970), "Increasing Risk: I. A Definition," Journal of Economic Theory, Vol. 2, Issue 3, 225-243

[32] Rubinstein, A., (1982), "Perfect Equilibrium in A Bargaining Model," Econometrica, 50, 97-110.

[33] Safra, Z., Zhou, L., and Zilcha, I., (1990), "Risk Aversion in Nash Bargaining Problems with Risky Outcomes and Risky Disagreement Points," Econometrica, 58, 961-965.

[34] Sobel, J., (1981), "Distortion of Utilities and the Bargaining Problem," Econometrica, 49, 597-620.

[35] Thomson, W., (1980), "The Manipulability of the Shapley Value," Mimeo, University of Minnesota, Minneapolis.

[36] Townsend, R., (1994), "Risk and insurance in village India," Econometrica, 62: 539-592.

[37] Wilson, R., (1968), "The Theory of Syndicates," Econometrica, vol. 36, 113-132 
[38] White, L., (2008), "Prudence in bargaining: The effect of uncertainty on bargaining outcomes," Games and Economic Behavior, 62, 211-231

\section{Appendix}

Claim When absolute risk tolerance is linear, the total certainty equivalent under efficient risk sharing is distributional free.

Proof. The set of Pareto-optimal allocations, or so-called Pareto efficient frontier, is give by: for some scalar $\lambda \in \mathbb{R}_{++}$and all $Y$, risk sharing rule $s(Y)$ solves the following maximization problem

$$
\max _{s}\left\{E u_{j}(Y-s)+\lambda E u(s)\right\}
$$

Solving for $u^{\prime}(s)=D_{1} t(s)^{-\gamma}$, where $D_{1}$ is a constant, from $t(s)=\frac{1}{\gamma} s+\frac{1}{\alpha}$ and combining with the F.O.C. of Pareto optimization (16), yields:

$$
s(\lambda)=\frac{\frac{\gamma}{\alpha}\left(1-\lambda^{\frac{-1}{\gamma}}\right)+Y}{1+\lambda^{\frac{-1}{\gamma}}}
$$

Substituting into the expression of risk tolerance yields:

$$
t(s)=\frac{\frac{\gamma}{\alpha}+Y}{\gamma\left(1+\lambda^{\frac{-1}{\gamma}}\right)} ; t(Y-s)=\frac{\lambda^{\frac{-1}{\gamma}}\left(Y+\frac{\gamma}{\alpha}\right)}{\gamma\left(1+\lambda^{\frac{-1}{\gamma}}\right)}
$$

Since $C(\lambda)=u^{-1}\left(E u(s(\lambda))+u^{-1}(E u(Y-s(\lambda)))\right.$, which after taking derivative w.r.t. $\lambda$ and combining with the expression of risk tolerance yields:

$$
\frac{\partial C}{\partial \lambda}=\gamma \frac{\partial}{\partial \lambda}\left(t\left(u^{-1}(E u(s(\lambda)))+t\left(u^{-1}(E u(Y-s(\lambda)))\right)\right)\right.
$$

Then, solving for $u(s)=\frac{\gamma}{1-\gamma} D_{1} t(s)^{1-\gamma}+D_{2}$, where $D_{1}, D_{2}$ are constants, and combining with the expression of risk tolerance, we have $t\left(u^{-1}(E u(s(\lambda)))=\left(E t(s(\lambda))^{1-\gamma}\right)^{\frac{1}{1-\gamma}}\right.$ and $t\left(u^{-1}(E u(Y-s(\lambda)))\right)=\left(E t(Y-s(\lambda))^{1-\gamma}\right)^{\frac{1}{1-\gamma}}$. Inserting into (18), we can easily derive $\partial v / \partial \lambda=0$.

Proof of $\frac{\partial^{2} \pi\left(k \varepsilon, w_{0}\right)}{\partial k \partial w_{0}} \leq 0$ 
Proof. Using the same technique for deriving (4), we have that $\frac{\partial^{2} \pi\left(k \varepsilon, w_{0}\right)}{\partial k \partial w_{0}} \leq 0$ is equivalent to

$$
E\left(t\left(w_{0}+k \tilde{\varepsilon}\right)^{-\gamma} \tilde{\varepsilon}\right) E\left(t\left(w_{0}+k \tilde{\varepsilon}\right)^{-\gamma}\right) \geq E\left(t\left(w_{0}+k \tilde{\varepsilon}\right)^{-(1+\gamma)} \tilde{\varepsilon}\right) E t\left(w_{0}+k \tilde{\varepsilon}\right)^{1-\gamma} .
$$

For $\gamma=1$, the above inequality is equivalent to

$$
\operatorname{Cov}\left(t\left(w_{0}+k \tilde{\varepsilon}\right)^{-1}, t\left(w_{0}+k \tilde{\varepsilon}\right)^{-1} \tilde{\varepsilon}\right) \leq 0 .
$$

But we know that $t\left(w_{0}+k \tilde{\varepsilon}\right)^{-1}$ is decreasing and $t\left(w_{0}+k \tilde{\varepsilon}\right)^{-1} \tilde{\varepsilon}$ is increasing when $\gamma=1$. Hence, the above inequality holds.

For the general case, let us examine first the case with discrete income distribution, from which continuous income distribution is a limiting case. Consider the probability distribution characterized by $p\left(\varepsilon=\varepsilon_{k}\right)=p_{k}$ with $\varepsilon_{1}<\varepsilon_{2}<\ldots<\varepsilon_{\infty}$. Denote $t_{k}=t\left(w_{0}+k \varepsilon_{k}\right)$. The necessary and sufficient condition for (19) writes as

$$
\sum_{k} p_{k} t_{k}^{-\gamma} \varepsilon_{k} \sum_{k} p_{k} t_{k}^{-\gamma} \geq \sum_{k} p_{k} t_{k}^{-(\gamma+1)} \varepsilon_{k} \sum_{k} p_{k k} t_{k}^{1-\gamma}
$$

which after rearranging is equivalent to

$$
\sum_{k>l} \sum_{l} p_{k} p_{l}\left(t_{k}^{-\gamma} \varepsilon_{k} t_{l}^{-\gamma}+t_{l}^{-\gamma} \varepsilon_{l} t_{k}^{-\gamma}-t_{k}^{-(\gamma+1)} \varepsilon_{k} t_{l}^{1-\gamma}-t_{l}^{-(\gamma+1)} \varepsilon_{l} t_{k}^{1-\gamma}\right) \geq 0 .
$$

The above holds for any discrete income distribution iff for all $x_{k}, x_{l}$,

$$
t_{k}^{-\gamma} \varepsilon_{k} t_{l}^{-\gamma}+t_{l}^{-\gamma} \varepsilon_{l} t_{k}^{-\gamma}-t_{k}^{-(\gamma+1)} \varepsilon_{k} t_{l}^{-\gamma}-t_{l}^{-(\gamma+1)} \varepsilon_{l} t_{k}^{-\gamma} \geq 0
$$

which is equivalent to

$$
\varepsilon_{k}+\varepsilon_{l}-t_{k}^{-1} \varepsilon_{k} t_{l}-t_{l}^{-1} \varepsilon_{l} t_{k} \geq 0,
$$

which is independent of $\gamma$. We already know (19) holds for $\gamma=1$, hence the above inequality must hold. Consequently (19) holds for all $\gamma$.

\section{Proof of existence and uniqueness of Nash solution on $S^{P}$ :}

Proof. We want to prove that the bargaining game $\left(S^{P}, d\right)$ has a unique solution. Nash (1950) proved that a bargaining game $(\widetilde{S}, d)$ has a unique solution if $\widetilde{S}$ is 
compact and convex. Obvious, $S^{P}$ is not convex and hence we can not apply his result directly. However, let

$$
\widetilde{S}=\left\{\alpha\left(u_{1}, u_{2}\right)+(1-\alpha)\left(u_{1}^{\prime}, u_{2}^{\prime}\right) \mid\left(u_{1}, u_{2}\right) \in S^{P},\left(u_{1}^{\prime}, u_{2}^{\prime}\right) \in S^{P}, 0 \leq \alpha \leq 1\right\} .
$$

Then, $\widetilde{S}$ is compact and convex. Hence, a unique solution exist for the bargaining game $(\widetilde{S}, d)$.

One can easily check that $S^{P}$ defines an implicit function, with $u_{2}$ being a decreasing and concave function of $u_{1}$. Indeed, $\left(u_{1}, u_{2}\right) \in S^{P}$ implies $u_{2}=u\left(C-u^{-1}\left(u_{1}\right)\right)$ and therefore

$$
\begin{gathered}
\frac{\partial u_{2}}{\partial u_{1}}=-u^{\prime}\left(C-u^{-1}\left(u_{1}\right)\right) \frac{1}{u^{\prime}\left(u^{-1}\left(u_{1}\right)\right)}<0, \\
\frac{\partial^{2} u_{2}}{\partial u_{1}^{2}}=\frac{u^{\prime \prime}\left(C-u^{-1}\left(u_{1}\right)\right)}{\left[u^{\prime}\left(u^{-1}\left(u_{1}\right)\right)\right]^{2}}+\frac{u^{\prime}\left(C-u^{-1}\left(u_{1}\right)\right) u^{\prime \prime}\left(u^{-1}\left(u_{1}\right)\right)}{u^{\prime}\left(u^{-1}\left(u_{1}\right)\right)^{3}}<0 .
\end{gathered}
$$

Hence, the Pareto frontier of $\widetilde{S}$ is exactly $S^{P}$. But we know that the Nash bargaining solution is Pareto optimal, hence it must belong to $S^{P}$. By the axiom of independence of irrelevant alternatives, the bargaining game $\left(S^{P}, d\right)$ and $(\widetilde{S}, d)$ have the same solution, which is unique. The solution is given by

$$
\begin{gathered}
\max _{\left(u_{1}, u_{2}\right)}\left(\left(u_{1}-u\left(C_{1}^{d}\right)\right) \cdot\left(u_{2}-u\left(C_{2}^{d}\right)\right)\right) \\
\text { s.t. }\left(u_{1}, u_{2}\right) \in S^{P},
\end{gathered}
$$

which is equivalent to our problem $P 2$.

\section{Proof of Lemma 5}

Proof. From (14), we have

$$
\frac{\widetilde{v}_{2}\left(N C-\widetilde{f}_{2}\left(a_{2}\right)\right)}{\widetilde{v}_{2}\left(N C-a_{2}\right)}=\frac{v_{2}\left(N C-f_{2}\left(a_{2}\right)\right)}{v_{2}\left(N C-a_{2}\right)}=\delta .
$$

To prove $\widetilde{f}_{2}\left(a_{2}\right)>f_{2}\left(a_{2}\right)$, it suffices to prove

$$
\frac{\widetilde{v}_{2}\left(N C-f_{2}\left(a_{2}\right)\right)}{\widetilde{v}_{2}\left(N C-a_{2}\right)}>\frac{v_{2}\left(N C-f_{2}\left(a_{2}\right)\right)}{v_{2}\left(N C-a_{2}\right)} .
$$

Rearranging it gives $\frac{\widetilde{v}_{2}\left(N C-f_{2}\left(a_{2}\right)\right)}{v_{2}\left(N C-f_{2}\left(a_{2}\right)\right)}>\frac{\widetilde{v}_{2}\left(N C-a_{2}\right)}{v_{2}\left(N C-a_{2}\right)}$. From (14), we know $N C-f_{2}\left(a_{2}\right)<$ $N C-a_{2}$. Thereby, we only need to prove $\frac{\widetilde{v}_{2}(x)}{v_{2}(x)}$ decreases in $x$.

$$
\frac{\partial}{\partial x} \frac{\widetilde{v}_{2}(x)}{v_{2}(x)}=\frac{\widetilde{v}_{2}^{\prime}(x) v_{2}(x)-\widetilde{v}_{2}(x) v_{2}^{\prime}(x)}{v_{2}^{2}(x)} .
$$


Hence, we need to prove

$$
\begin{gathered}
\widetilde{v}_{2}^{\prime}(x) v_{2}(x)-\widetilde{v}_{2}(x) v_{2}^{\prime}(x)<0 \\
\Leftrightarrow \frac{\widetilde{v}_{2}^{\prime}(x)}{\widetilde{v}_{2}(x)}<\frac{v_{2}^{\prime}(x)}{v_{2}(x)} \\
\Leftrightarrow \frac{\widetilde{v}_{2}^{\prime}(x)}{\int_{0}^{x} \widetilde{v}_{2}^{\prime}(s) d s}<\frac{v_{2}^{\prime}(x)}{\int_{0}^{x} v_{2}^{\prime}(s) d s} \\
\Leftrightarrow \int_{0}^{x} \frac{\widetilde{v}_{2}^{\prime}(s)}{\widetilde{v}_{2}^{\prime}(x)} d s>\int_{0}^{x} \frac{v_{2}^{\prime}(s)}{v_{2}^{\prime}(x)} d s \\
\Leftrightarrow \int_{0}^{x}\left(\frac{\widetilde{v}_{2}^{\prime}(s)}{\widetilde{v}_{2}^{\prime}(x)}-\frac{v_{2}^{\prime}(s)}{v_{2}^{\prime}(x)}\right) d s>0 \\
\Leftarrow \frac{\widetilde{v}_{2}^{\prime}(s)}{\widetilde{v}_{2}^{\prime}(x)}-\frac{v_{2}^{\prime}(s)}{v_{2}^{\prime}(x)}>0, \forall s<x, \\
\Leftrightarrow \frac{\widetilde{v}_{2}^{\prime}(s)}{v_{2}^{\prime}(s)}>\frac{\widetilde{v}_{2}^{\prime}(x)}{v_{2}^{\prime}(x)}, \forall s<x,
\end{gathered}
$$

which will hold if $\frac{\widetilde{v}_{2}^{\prime}(s)}{v_{2}^{\prime}(s)}$ is decreasing in $s$.

$$
\frac{\partial}{\partial s}\left(\frac{\widetilde{v}_{2}^{\prime}(s)}{v_{2}^{\prime}(s)}\right)=\frac{\widetilde{v}_{2}^{\prime \prime}(s) v_{2}^{\prime}(s)-v_{2}^{\prime \prime}(s) \widetilde{v}_{2}^{\prime}(s)}{v_{2}^{\prime 2}(s)}<0,
$$

$\Leftrightarrow$

$$
-\frac{\widetilde{v}_{2}^{\prime \prime}(s)}{\widetilde{v}_{2}^{\prime}(s)}>\frac{-v_{2}^{\prime \prime}(s)}{v_{2}^{\prime}(s)} .
$$

